\title{
Llegar a ser una perífrasis es fácil con los verbos de movimiento. La evolución de llegar a + INFinitivo en español
}

\author{
Mar Garachana ${ }^{1}$ \\ Universitat de Barcelona, España
}

\begin{abstract}
Resumen
En este artículo se analiza la evolución de la perífrasis verbal llegar $a+$ INF desde los planteamientos teóricos de la gramática de construcciones diacrónica. El estudio prueba que esta perífrasis verbal conforma una categoría radial en la que se agrupan microconstrucciones diferentes, estrechamente conectadas entre sí. La evolución de la perífrasis parte del siglo XIII, cuando se documentan las microconstrucciones que expresan (i) conclusión de una serie de eventos previos, (ii) capacidad y (iii) logro. En el siglo XVI se añaden los valores focalizadores $\mathrm{y}$, finalmente, en el siglo XVII surge una construcción que expresa posibilidad.
\end{abstract}

Palabras clave: llegar a + INFINITIVO, perífrasis verbales, gramática de construcciones diacrónica, gramaticalización.

1 Para correspondencia, dirigirse a: Mar Garachana Camarero (margarachana@ub.edu), Universidad de Barcelona. Gran Via de les Corts Catalanes, 585. 08007 Barcelona. España. 


\title{
BECOMING A VERBAL PERIPHRASIS IS EASY WITH VERBS OF MOVEMENT. THE EVOLUTION OF SPANISH LLEGAR A + INFINITIVE
}

\begin{abstract}
This article focuses on the evolution of the Spanish verbal periphrasis llegar $a+$ INF (lit. to arrive to + INF) following the theoretical methodology established by Diachronic Construction Grammar. The study proves that llegar $a+$ INF forms a radial category in Spanish in which different, closely connected microconstructions are grouped together. The evolution of the periphrasis begins in the 13th century, with microconstructions that express (i) the ending of a series of previous events, (ii) ability and (iii) achievement. Focusing values were added in the 16th century, and finally, in the 17th century, a construction emerged that expresses possibility.
\end{abstract}

Keywords: llegar $a+$ InFInITIVE, verbal periphrases, diachronic construction grammar, grammaticalization.

Recibido: 10/06/19 Aceptado:09/08/19

\section{INTRODUCCIÓN ${ }^{2}$}

El objetivo del presente trabajo es estudiar la evolución de la perífrasis verbal llegar a + INF. Esta construcción se documenta desde los primeros textos escritos en castellano con valores diversos, relacionados todos de una forma u otra con la idea de alcanzar una meta. Se trata, pues, de un caso de persistencia del significado de llegar cuando funciona como verbo pleno, en el sentido de Hopper (1991). Es decir, en las diferentes construcciones asociadas a la forma llegar $a+\mathrm{INF}$, subyace una idea de trayectoria que se concreta en valores diversos.

En algunos de sus empleos, llegar $a+$ INF introduce el último de una serie de eventos, ya sea de una manera neutra (1a) o con un matiz intensificador

2 Quiero hacer constar mi más sincero agradecimiento a Malte Rosemeyer y a Hella Olbertz, cuyas sugerencias y propuestas de cambio han mejorado indudablemente este trabajo. Asimismo, quiero agradecer a los miembros del equipo Gradia la atenta lectura que hicieron de este texto y las largas discusiones que mantuvimos. Por último, quiero agradecer a Martin Hilpert su ayuda con ciertos conceptos clave de la gramática de construcciones diacrónica. Los errores son, en todo caso, de mi entera responsabilidad. 
(1b). En (1a) habian llegado a considerar supone el final de un período en el que el Magistral no era considerado el único confesor de buen tono: la perífrasis marca un cambio, una interrupción de una situación, que comporta que el Magistral acabe por ser merecedor de dicha consideración. En (1b) llegaba a cansar implica, igualmente, una etapa anterior en la que la alabanza acerca de la impecabilidad moral de la Regenta no era cansina para la ciudad de Vetusta. La perífrasis marca el punto en el que la ciudad se aburre de tanta loanza.

1. a. Las damas de ciertas pretensiones habían llegado a considerar en el Magistral el único confesor de buen tono. (Leopoldo "Alas" Clarín, La Regenta, siglo XIX, GRADIA)

b. La aburría tanta alabanza. Toda Vetusta diciendo: “ ¡La Regenta, la Regenta es inexpugnable!”. Al cabo llegaba a cansar aquella canción eterna. Hasta el modo de llamarla era tonto. ¡La Regenta! (Leopoldo "Alas" Clarín, La Regenta, siglo XIX, GRADIA)

En otros de sus usos, llegar $a+$ INF se emplea para expresar la culminación de una meta, esto es, un logro (2a). En este caso, el recorrido metafórico expresado por la perífrasis culmina con la consecución de un objetivo. Llegar $a+$ INF reviste también empleos escalares focalizadores como los de (2b), que en ocasiones pueden atenuarse hasta hacer débil la diferencia entre la forma simple y la perifrástica (2c). En ambos casos, hay una idea de trayecto que se cierra con la formulación de la perífrasis. Por último, llegar a + INF significa la capacidad o incapacidad del sujeto para emprender ciertas acciones (2d), desde donde se extiende hasta sentidos de posibilidad (2e). Nuevamente, en los valores de posibilidad y en los de capacidad se intuye una idea de recorrido metafórico que se cierra con el evento presentado por la perífrasis.

2. a. DEB: sí / tienes que / practicar mucho para llegar a ser / como Michael $<$ Schumacher $>$. (C-ORAL, siglo xx, GRADIA)

b. Esta apología está escrita con gran calor: llega a acusar de sabelianos y antitrinitarios a los que practicaban la simple mersión. (Menéndez Pelayo, Historia de los heterodoxos españoles, siglo XIX, GRADIA)

c. Enc.- ¿Y a usted le llegaron a abrir? (Juan M. Lope Blanch, El habla popular de la ciudad de México. Materiales para su estudio, siglo XX, GRADIA)

d. En este mitin, es ella una vez más, tan ella, tan igual a sí misma, a su leyenda, que nadie llega a apreciar diferencia alguna con otras tardes, otros mítines, y sin embargo, ya es distinta, tiene que serlo. (Almudena Grandes, Inés y la alegría, siglo xxi, Gradia) 
e. La otra se apartó, echando llamas de sus ojos y resoplidos de su pecho, y andando hacia atrás siguió diciendo, sin que las palabras llegaran a articularse. (Benito Pérez Galdós, Fortunata y Jacinta, siglo XIX, GRADIA)

El estudio que llevaremos a cabo tratará de dar respuesta a la pregunta de cómo se va configurando esta tupida red de valores a lo largo del tiempo. Para ello, este trabajo se basará en el marco teórico de la gramática de construcciones diacrónica. Los ejemplos en los que fundamentaremos nuestro análisis proceden de una extracción exhaustiva de ejemplos del corpus multimodal GRADIA ${ }^{3}$. Hemos obtenido así un total de 8386 ocurrencias en las que aparece el verbo llegar, de las que 1578 son construcciones perifrásticas. De estas, para los cálculos estadísticos y de porcentajes solo tomamos 1412, ya que omitimos las construcciones en las que la perífrasis está cerca de su sentido etimológico de movimiento.

Este trabajo se articula en 6 apartados, además de la presente introducción. En el apartado 2 realizaremos una breve contextualización de nuestro estudio en el marco de la gramática de construcciones diacrónica. En el apartado 3, propondremos un breve repaso bibliográfico de los estudios existentes de llegar a + INF. En los apartados 4, 5 y 6 nos ocuparemos de la evolución de llegar $a+$ INF en español. Finalmente, en el apartado 7, presentaremos las conclusiones a las que lleguemos.

\section{GRAMÁTICA DE CONSTRUCCIONES DIACRÓNICA. SU INTERÉS PARA EL ESTUDIO DE LA HISTORIA DE LLEGAR A + INF}

La gramática de construcciones diacrónica puede considerarse la vertiente diacrónica de la Lingüística Cognitiva. Dentro de este enfoque teórico

\footnotetext{
3 El corpus Gradia (<https://Gradiadiacronia.wixsite.com/Gradia/corpus-Gradia $>$ ) es un corpus multimodal que incluye textos desde el siglo XII hasta el siglo XXI pertenecientes a tipologías textuales diversas (texto legal, notarial y administrativo, historiográfico, técnico, narrativo, ensayístico, epistolar, sapiencial, discursos políticos, diálogos renacentistas, prensa escrita, teatro y textos orales). La razón última de esta diversificación textual obedece a que esta es la única manera fiable de poder asegurar que un determinado fenómeno no responde a una moda retórica o a preferencias particulares de autores concretos, sino a tendencias de la lengua.
} 
empezó a desarrollarse a finales de la década de los ochenta la gramática de construcciones, una aproximación al estudio del lenguaje que centraba su atención en las construcciones gramaticales, consideradas la unión de una forma con un significado no composicional (Fillmore y Kay 1997; Fillmore, Kay, y O’Connor 1988; Fillmore 1988; Kay y Fillmore 1999). Los primeros trabajos se centraban en construcciones idiomáticas, como el inglés let alone, pero la consideración última era analizar las regularidades gramaticales que se descubrían en la fraseología y que hacían imposible memorizar sin más las frases hechas (para el español, vid. Hilferty, Valenzuela y Garachana 2005).

Las conclusiones de los estudios sobre gramática de construcciones permitieron proponer que el análisis construccional podía aplicarse no solo al estudio del léxico, sino también de la gramática (Lakoff 1987). Es así como se llega a la formulación del concepto de construcción gramatical como la unión convencionalizada de una forma con un significado (Goldberg 2006). Las construcciones gramaticales abarcan desde los sufijos o los morfemas hasta las oraciones, en el plano gramatical, pero dan cabida también a las palabras léxicas o a las construcciones idiomáticas. No se establece, pues, una frontera neta entre léxico y gramática. Las construcciones se almacenan en el constructicón, una especie de repositorio de construcciones, organizadas en diferentes niveles de esquematicidad. Así, en el terreno de las perífrasis, encontramos un esquema genérico $[\mathrm{v}+\mathrm{v}]$ que se concreta en subesquemas particulares tales como [llegar a + INF], [ir + GER], [estar + PART] o [ir y + VERBO FINITO]. Cada uno de estos subesquemas acoge microconstrucciones particulares, que pueden recubrir significados diversos y que se actualizan en constructos, esto es, en el empleo de estas perífrasis en enunciados particulares.

En este trabajo, nos interesa trabajar con la idea de la esquematicidad, dado que la perífrasis que nos ocupa, llegar a + INF, expresa valores diferentes que no se reducen a una interpretación en términos de polisemia (vid. apartado 1). En efecto, no solo es diferente el significado que expresan las diferentes microconstrucciones vinculadas a llegar $a+$ INF (vid. apartado 1), sino que la combinatoria sintáctica y la propia morfología de cada uno de los diferentes significados muestra especificidades particulares. Dado que nuestro interés es fundamentalmente diacrónico, nos va a interesar de manera particular cómo afloran en la lengua española los nuevos emparejamientos de forma y de función que conforman las diferentes microconstrucciones que se agrupan bajo la forma esquemática llegar $a+$ INF. 


\section{LLEGAR A + INF EN LA BIBLIOGRAFÍA LINGÜÍSTICA}

Apenas existen trabajos sobre la historia de llegar a + INF en la bibliografía lingüística. Merecen ser reseñados el estudio de Yllera (1980), quien describe brevemente la trayectoria histórica de la perífrasis hasta el siglo xv, y la referencia contenida en Olbertz (1998: 261). En contrapartida, el interés sincrónico por esta perífrasis, sin que pueda considerarse extenso, ha sido lo suficientemente relevante como para disponer en el momento actual de una descripción bastante completa de la mayoría de sus valores.

Salvo excepciones (Morera Pérez 1991: 122-128), llegar $a+$ INF se incluye en la nómina de las perífrasis verbales ${ }^{4}$. La caracterización más extendida suele incluirla entre las perífrasis aspectuales. Así, se la califica de perífrasis perfectiva (Gili y Gaya 1961), perfectiva-terminativa (García González 1992: 74), terminativa (Fente Gómez, Fernández Álvarez y Feijóo 1979; Gómez Torrego 1988: 121) o culminativa (Fogsgaard 2002; Olbertz 1998, 418-22; Fernández de Castro 1999: 300-306). Habitualmente, se la describe, pues, como una construcción gramatical que presenta el fin del evento expresado por el infinitivo (o bien la aproximación a dicho fin). En la misma línea, Pountain (1984: 106) considera que llegar a + INF es una expresión inceptiva.

Existen, con todo, excepciones a esta descripción ligada al aspecto, incluso dentro de trabajos que adscriben la perífrasis a esta categoría gramatical. Así, Dietrich (1983), Gómez Manzano (1992) y Fernández de Castro (1999: 281) coinciden en subrayar que llegar $a+$ INF presenta el evento que expresa el infinitivo como parte de otra cosa. De la misma manera, Gómez Torrego (1999: 3384-3385), quien considera que el valor básico de llegar a + INF es el de logro (vid. también Gómez Torrego 1988: 121), añade que tiene sentidos que la vinculan con la idea de "la culminación de un proceso", de modo que es equivalente a "finalmente, al fin, incluso" (Gómez Torrego 1988: 122 y 1999: 3384-3385). A su vez, Olbertz (1998), quien como decíamos vincula la perífrasis al aspecto ingresivo, señala asimismo que se trata de una perífrasis de evaluación actual, de manera que el empleo de la perífrasis supone que el evento que se presenta no era esperado en la situación comunicativa en la que se utiliza (Olbertz 1998:

\footnotetext{
4 Olbertz (1998: 257), aunque admite el carácter perifrástico de llegar a + INF, señala que "the periphrastic status of llegar a + infinitive is less obvious than that of the other constructions to be discussed in this section".
} 
416-430). Y en la misma línea se encuentra Fogsgaard (2002), para quien esta perífrasis, que incluye en una monografía sobre las perífrasis aspectuales del español, recubre un marcado sentido modal. Estas ideas, que alejan a nuestra construcción de los valores aspectuales, han sido desarrolladas por Carrasco Gutiérrez $(2006,2008)$, para quien la perífrasis tiene el comportamiento de un marcador discursivo de naturaleza aditiva.

Si recordamos los valores de llegar $a+$ INF que presentábamos en la introducción, se pone de relieve que la descripción que mejor conviene al empleo de llegar a + INF es la que realiza Carrasco (2006, 2008), siguiendo ideas contenidas en otros autores anteriores (Dietrich 1983; Gómez Manzano 1992; Fernández de Castro 1999, Gómez Torrego 1988, 1999; Olbertz 1998).

Como venimos diciendo, llegar $a+$ INF suele introducir un evento (el expresado por el infinitivo) que se sitúa al final de una secuencia más amplia, que puede quedar explicitada o no. Por lo tanto, la perífrasis permite presentar hitos representativos o remarcables en la exposición (vid. Fernández de Castro 1999: 301). Este valor puede presentarse de manera intensiva o ponderativa en los contextos en que la perífrasis tiene un valor sinónimo de incluso (vid. Carrasco 2006: 189; Fernández de Castro 1999: 303; Gómez Torrego 1988: 122 y 1999: 3384-3385). De este modo, podemos considerar que la perífrasis ofrece un sentido interruptivo como el que presentan Jaque et al. (este volumen) en su trabajo sobre llegar y + $\mathrm{v}$, si bien ambas construcciones tienen valores claramente individualizados. El punto de contacto entre llegar a + INF y llegar y $+\mathrm{v}$ tiene que ver con que en ambos casos la construcción verbal introduce el final de una serie de hechos previos, con lo que se interrumpe dicha secuencia. De ahí que algunos autores hayan considerado que llegar a + INF sirve para introducir nuevos eventos (Pountain 1984 y Olbertz 1998).

La perífrasis tiene un valor discursivo en la medida en que presenta el último elemento dentro de una serie argumentativa más amplia (explícita o no). Aquí creemos que radica la confusión relativa a la clasificación de esta perífrasis. De algún modo, llegar a + INF expresa la culminación de una serie de eventos (el final) y, por este motivo, ha podido ser considerada una perífrasis aspectual. Ahora bien, como se señala en Carrasco Gutiérrez $(2006,2008)$ el sentido culminativo de llegar $a+$ INF no tiene que ver con la culminación del evento expresado por el infinitivo ${ }^{5}$, sino con el final de una serie de eventos co(n)textualmente dados o inferidos (vid., asimismo,

\footnotetext{
Como sostiene Carrasco (2008: 83): Nosotros no creemos que <llegar $a+$ infinitivo $>$ sea una perífrasis de fase Terminativa, sino una construcción que sitúa el evento denotado por el infinitivo en un lugar destacado de una serie.
} 
Olbertz 1998: 419). Con la perífrasis no se indica ni el final, ni que nos acerquemos al final del evento indicado por el infinitivo, sino la culminación de una secuencia previa ${ }^{6}$. Así las cosas, coincidimos con Carrasco (2008) en que no estamos ante una perífrasis aspectual, a menos que la tratemos como una representante del aspecto interruptivo, como se hace en Jaque et al. ( $\rightarrow$ este volumen) para la descripción de la construcción llegar $y+\mathrm{V}$.

Carrasco (2008) proporciona argumentos sintácticos para ratificar su argumentación. Concretamente, señala que si bien la perífrasis llegar a INF entra en estructuras con lecturas perfectivas (3) y resultativas (4), lo que podría hacer pensar en un valor perfectivo o resultativo de la construcción, lo cierto es que estos valores dependen del tiempo en que se conjuga el auxiliar. Además, otras propiedades le niegan tal estatus categorial. Así, la perífrasis puede emplearse con predicados atélicos, que no marcan límites (5), o con verbos que expresan un aspecto prospectivo, lo que hace imposible contemplar su finalización (6).

3. a. María había llegado a escribir una novela aquel año. (Carrasco 2008: 77)

b. María había llegado a escribir la carta a las tres. (Carrasco 2008: 78)

c. Había llegado a firmar el documento cuando todos se pusieron de acuerdo. (Carrasco 2008: 78)

4. a. Aquel año, María ya había llegado a escribir una novela. (Carrasco 2008: 77)

b. A las tres, María ya había llegado a escribir la carta

c. Cuando todos se pusieron de acuerdo, ya había llegado a firmar el documento

5. Durante la reunión llegaba a mirarla desafiante. (Carrasco 2008: 79)

6. Nos dijo que iba a llegar a escribir una novela, (pero ahí sigue, sin escribir ni una sola página). (Carrasco 2008: 79)

Tampoco parece que pueda considerarse que llegar a + INF es una perífrasis terminativa, pues, como ya hemos dicho no expresa el final o la culminación del evento expresado por el infinitivo, a diferencia, por ejemplo, de dejar de

\footnotetext{
6 Probablemente por este mismo motivo Olbertz (1998) considera que hay una relación entre esta perífrasis y el aspecto ingresivo, pues al marcar el final de una secuencia de eventos, puede servir para indicar el comienzo del estado de cosas cuando se construye con predicatos estativos (Olbertz 1998: 421).
} 
+ INF o de acabar de + INF. En efecto, acabar de cenar a medianoche o dejar de cenar a medianoche significan que la cena concluye a las 12 de la noche. En cambio, llegó a cenar a medianoche no dice nada sobre la finalización del acto de cenar. Más bien, señala lo extraño o poco esperable de cenar a esa hora. Esta diferencia de significado, tiene un correlato sintáctico inmediato. Así, frente a acabar de + INF, llegar a + INF no solo se construye con predicados télicos que denotan eventos delimitados (realizaciones y logros). A su vez, dejar de + INF puede construirse con actividades, realizaciones y estados permanentes, pero no con estados permanentes, ni logros -excepto con lecturas habituales o iterativas (Cervantes ha dejado de estar muerto, * He dejado de encontrar tu cartera, El tren ha dejado de llegar a las tres y media, La ciencia dejará algún día de descubrir nuevos materiales, Camus Bergareche 2006, 118). Llegar a + INF no presenta esta restricción: admite en la posición de verbo auxiliado tanto predicados durativos como predicados no durativos (Carrasco 2008: 82 y ss.).

Otra razón para no considerar que llegar $a+$ INF sea una perífrasis culminativa o terminativa es el hecho de que el evento expresado por el infinitivo no se presenta como si tuviese un fin natural. Y, por último, la perífrasis no modifica el aspecto léxico del verbo en infinitivo y lo convierte en un predicado delimitado (Carrasco 2008: 84-86).

No vamos a entrar en la consideración de si llegar a + INF tiene un valor de conector o no (propuesta contenida en García Fernández et al. 2006; García Fernández y Carrasco Gutiérrez 2008; Carrasco Gutiérrez 2008), ya que no es este nuestro cometido, pero sí queremos subrayar que su empleo tiene que ver con la organización de la materia discursiva en el texto oral y escrito. Para definir estos valores, vamos a emplear la denominación de valor completivo o conclusivo, en el sentido de que la perífrasis completa una serie de acciones o de eventos previos.

Para finalizar este apartado, queremos señalar otra cuestión reseñada en la bibliografía sobre el tema, que tiene que ver con la aparición de esta perífrasis en contextos negados, o de significación negativa. En este sentido, convenimos con Fernández de Castro (1999: 291-293) en que esta afinidad por los contextos negativos puede venir determinada por el propio valor finalizador de la perífrasis, que a menudo se utiliza para señalar el final de una serie de hechos positivos o la claudicación del sujeto de la perífrasis. A su vez Fogsgaard (2002: 128 y 130-131) señala que este matiz negativo tiene una correlación con el sentido contraexpectativo y de imposibilidad que se reconoce en muchos de los ejemplos con llegar $a+$ INF. Significativamente, en llegar $a+$ INF se han señalado, erróneamente creemos, significados contrafácticos (Fernández de Castro 1999: 306; Gómez Torrego 1988: 123; Olbertz 1998: 261; RAE y ASALE 2009: 3575). 


\section{LA HISTORIA DE $L L E G A R A+$ INF. GENERALIDADES}

El desarrollo de llegar a + INF tiene que ponerse en relación, necesariamente, con la aparición en la lengua de perífrasis verbales procedentes de verbos de movimiento. El carácter deíctico de estas piezas léxicas, que acostumbran a focalizar el lugar hacia el que se dirige el movimiento, es la clave de la evolución de muchas construcciones perifrásticas.

En efecto, verbos como llegar, ir o venir perspectivizan el lugar hacia el que el sujeto verbal se dirige. Así, llegar a casa, ir a casa o venir a casa marcan trayectorias que culminan en el sintagma preposicional locativo que subcategorizan. Cuando la construcción de verbo + sP se combina con un verbo en infinitivo, a la idea de movimiento se le añade un matiz de finalidad. De este modo, llegar a casa a comer, ir a casa a comer o venir a casa a comer permiten la conmutación de la preposición a por para (llegar a casa para comer, ir a casa para comer, venir a comer). Si se omite el sintagma preposicional que expresa el lugar al que se dirige el movimiento, la focalización característica de los verbos de movimiento sigue presente, si bien en estos casos se orienta al infinitivo. Llegar a comer, ir a comer, venir a comer describen situaciones en los que llegar, ir y venir subrayan el evento expresado por el infinitivo. Más aún, cuando se consuma la gramaticalización de la nueva construcción se llega a estructuras en las que resulta imposible introducir una indicación de lugar o alterar el orden de los constituyentes (A comer llegó tarde-? A ser presidente llegó; ?Llegó a ser presidente del gobierno español en su casa).

Este tipo de reanálisis permite que la combinación de verbo de movimiento + INF pueda gramaticalizarse para expresar otros significados, diferentes de la intención, relacionados con la idea de alcanzar un estado o completar un evento. Dicho de otra manera, la reorganización de la jerarquía de constituyentes de llegar $+\mathrm{SP}($ LOCATIVO) $+\mathrm{SP}($ INTENCIONALIDAD) $\rightarrow$ llegar $a+$ INF va acompañada de un cambio semántico que permite que la noción de 'alcanzar un lugar' se reanalice para significar que se alcanza un evento. Así las cosas, forma y significado interaccionan en la creación de la perífrasis llegar $a+$ INF: la posibilidad de omitir el complemento de lugar permite la combinación de llegar a con un infinitivo y que, de este modo, llegar perspectivice el evento expresado por este. De este modo, se favorece la emergencia de un nuevo significado asociado a la construcción: llegar a + INF indica el final de una serie de eventos previos (vid. para la afinidad entre llegar a + INF y acabar por + INF, Fente Gómez, Fernández Álvarez y Feijóo 1979: 52-53; Gómez Torrego 1988: 123-24; Olbertz 1998: 416-30; Fernández 
de Castro 1999: 304-305; Fogsgaard 2002: 133-38). Estamos ante un caso de construccionalización en el sentido de la gramática de construcciones diacrónica, ya que una nueva forma se asocia a un nuevo significado.

La persistencia del significado etimológico de llegar resulta visible en la noción de duración o de trayectoria que acompaña a la construcción perifrástica en sus diferentes acepciones. Como hemos indicado, en los diferentes valores de la perífrasis está implícita la idea de un recorrido previo que culmina con el evento expresado por llegar $a+$ INF (vid. apartado 1). Por lo demás, los diferentes matices de significado asociados a la construcción tienen que ver con su combinatoria (tipo de sujeto y colocados léxicos en la posición del verbo auxiliado) y con la propia morfología del verbo auxiliar.

La perífrasis llegar $a+\mathrm{INF}$, documentada desde los orígenes de la lengua, tiene una frecuencia de empleo ascendente a lo largo de los siglos (vid. Tabla 1). Mientras que en la etapa medieval su presencia es baja, a partir del siglo XVI, se inicia un ascenso que supone que, de esta centuria a la siguiente, la frecuencia de empleo de la perífrasis se duplique. El XIX, un siglo clave para la evolución del sistema perifrástico del español (Garachana Camarero 2017a), significa un nuevo impulso para la perífrasis, que mantiene más o menos la misma frecuencia en el siglo siguiente (en torno a las 200 apariciones por cada millón de palabras).

\begin{tabular}{|l|r|r|r|}
\hline & $\begin{array}{r}\text { Frecuencia absoluta } \\
\text { de la perífrasis }\end{array}$ & $\begin{array}{r}\text { Total de palabras } \\
\text { en el corpus }\end{array}$ & $\begin{array}{r}\text { Frecuencia por } \\
\text { millón de palabras }\end{array}$ \\
\hline XIII & 9 & 2745347 & 3,27 \\
\hline XIV & 5 & 1653131 & 3 \\
\hline XV & 3 & 1466863 & 2 \\
\hline XVI & 149 & 3603987 & 41 \\
\hline XVII & 184 & 2108281 & 87 \\
\hline XVIII & 78 & 1309491 & 60 \\
\hline XIX & 526 & 1916754 & 274 \\
\hline XX & 511 & 2542573 & 200 \\
\hline
\end{tabular}

Tabla 1. Frecuencia de empleo de llegar $a+$ INF por millón de palabras (siglos XIII-XX) 
En relación con la evolución diacrónica de los diferentes significados de llegar $a+$ INF, lo más remarcable es el hecho de que hasta el siglo XVI la perífrasis se documenta con valores de conclusión o interrupción de una serie previa, de logro o de capacidad. Los Siglos de Oro ven surgir los valores de focalización y de posibilidad. Si observamos la Tabla 2, podremos ver que, dejando a un lado el período medieval, cuando la frecuencia absoluta de la construcción resulta muy limitada, hasta el siglo XVIII el significado central de la perífrasis fue el de logro. A partir de esa fecha, los sentidos conclusivo y focalizador concentran la mayor proporción de los empleos de esta perífrasis, que siempre se ha empleado en una muy baja frecuencia con valor de posibilidad.

\begin{tabular}{|l|r|r|r|r|r|}
\hline siglo & $\begin{array}{r}\text { Valor } \\
\text { conclusivo }\end{array}$ & Capacidad & $\begin{array}{r}\text { Significado } \\
\text { focalizador }\end{array}$ & Logro & Posibilidad \\
\hline & $33,3 \%$ & $33,3 \%$ & & & \\
XIII & $(2 / 6)$ & $(2 / 6)$ & ----- & $33,3 \%(2 / 6)$ & ----- \\
\hline & $25 \%$ & & & & \\
XIV & $(1 / 4)$ & & ----- & $75 \%(3 / 4)$ & ---- \\
\hline & $66,6 \%$ & $33,3 \%$ & & & \\
XV & $(2 / 3)$ & $(1 / 3)$ & ----- & & ---- \\
\hline & $16,6 \%$ & $15,87 \%$ & $34,9 \%$ & $31,74 \% \%$ & \\
XVI & $(21 / 126)$ & $(20 / 126)$ & $(44 / 126)$ & $(40 / 126)$ & ---- \\
\hline & $13 \%$ & $26 \%$ & $27,9 \%$ & $31,6 \%$ & $1,24 \%$ \\
XVII & $(21 / 161)$ & $(42 / 161)$ & $(45 / 161)$ & $(51 / 161)$ & $(2 / 161)$ \\
\hline & $33,3 \%$ & $14,10 \%$ & $30,76 \%$ & $16,6 \%$ & \\
XVIII & $(26 / 78)$ & $(11 / 78)$ & $(24 / 78)$ & $(13 / 78)$ & $2,56 \%(2 / 78)$ \\
\hline & $26,9 \%$ & $14,5 \%$ & $37,4 \%$ & $17,74 \%$ & $3,43 \%$ \\
XIX & $(141 / 524)$ & $(76 / 524)$ & $(196 / 524)$ & $(93 / 524)$ & $(18 / 524)$ \\
\hline & $24,7 \%$ & $15,68 \%$ & $39,21 \%$ & $19,21 \%$ & $1,17 \%$ \\
XX & $(126 / 510)$ & $(80 / 510)$ & $(200 / 510)$ & $(98 / 510)$ & $(6 / 510)$ \\
\hline
\end{tabular}

Tabla 2. Distribución histórica de los significados asociados a llegar a + INF

La evolución en forma de campana invertida no perfecta que se detecta en el empleo de los valores de logro y de capacidad no puede ser únicamente explicada desde la propia perífrasis (vid. Tabla 2 y Gráficos 1 y 2 ) $^{7}$.

7 Uno de los revisores anónimos señaló, muy acertadamente, que la frecuencia de la perífrasis en los primeros siglos es casi despreciable. Pese a ello, las hemos mantenido, a 


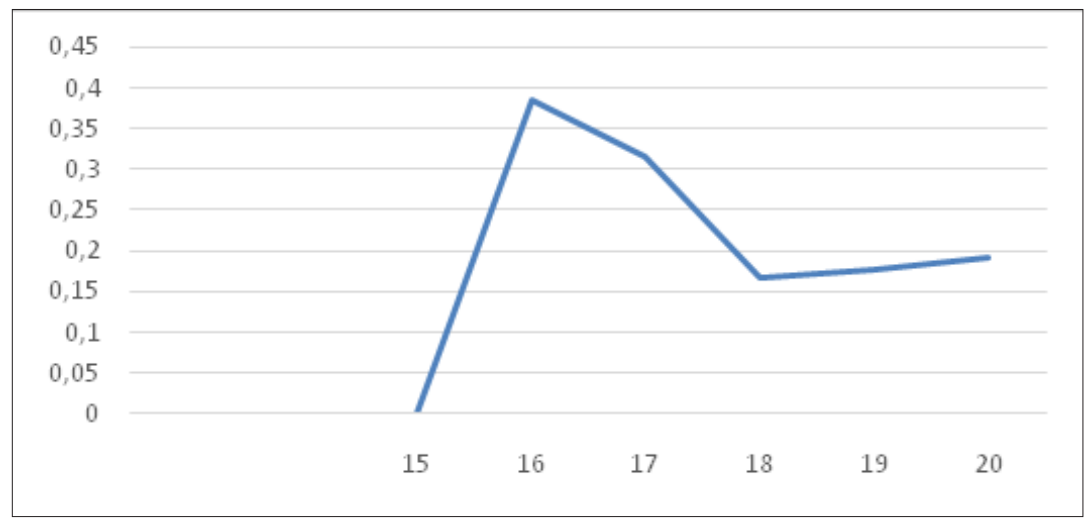

Gráfico 1. Evolución de los significados de logro asociados a llegar a + INF

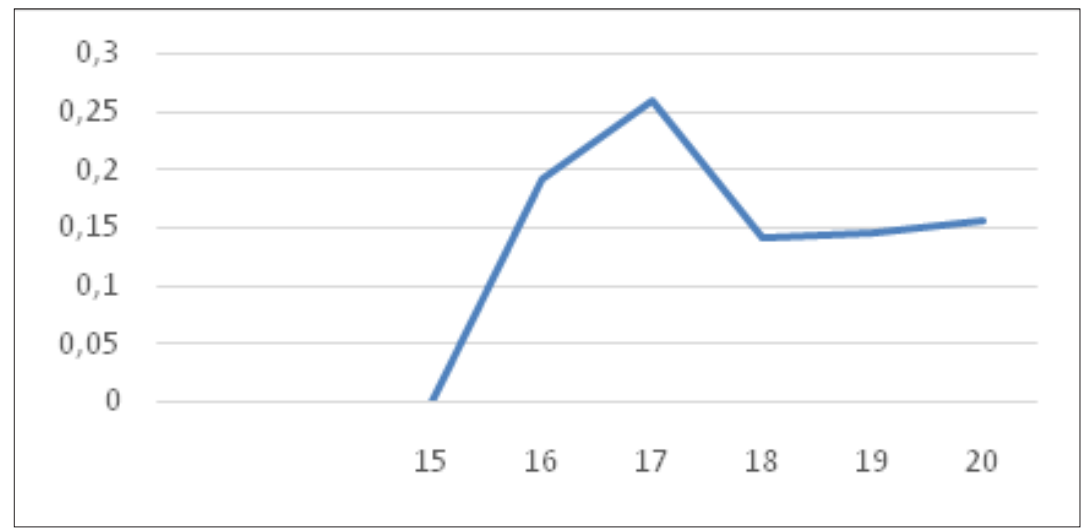

Gráfico 2. Evolución de los significados de capacidad asociados a llegar $a+\mathrm{INF}$

El comportamiento de esta construcción en las lecturas de logro y de capacidad solo puede entenderse si lo contemplamos en la perspectiva global de la evolución de las perífrasis verbales del español. En efecto, como se prueba en Rosemeyer y Garachana (2019), el siglo XVIII supone la emergencia de dos construcciones que disputarán a llegar $a+$ INF la expresión de los logros y de la capacidad, a saber, lograr + INF y conseguir + INF. La aparición

sabiendas de que estos porcentajes no resultan significativos para la evolución de la perífrasis, más allá de probar que se trata de construcciones que ya se pueden recoger en la lengua del XIII, del XIV y del XV. Es por este motivo que en las gráficas 1 y 2, los primeros siglos han sido eliminados. 
de estas dos construcciones multiverbales bien pudo motivar la redistribución de los sentidos vinculados a llegar a + INF. Aunque lograr + INF y conseguir + INF tienen asociados otros valores, la persistencia del significado del verbo auxiliar en sus usos como verbo pleno (lograr/conseguir) permite entender que estas dos formas quitasen terreno a llegar $a+$ INF, que, a su vez, bien pudo funcionar a modo de construcción soporte que activase su gramaticalización, como se propone en Rosemeyer y Garachana (2019). Posiblemente, sea también la competencia con estas perífrasis (y con poder + INF) la que determine la caída del empleo de los valores de capacidad de llegar a + INF. Los valores más claramente ligados al alcance de un límite (los significados de conclusión o finalización de una serie previa y de focalización) han resultado ser los que más caracterizan nuestra perífrasis. Probablemente, ello tenga que ver con el hecho de que no experimentaron de forma tan marcada la competencia de otras construcciones multiverbales.

\section{LLEGAR A + INF: LA CONSTITUCIÓN DE UNA CATEGORÍA RADIAL}

En este apartado, vamos a ocuparnos de la evolución de llegar $a+$ INF y vamos a tratar de demostrar que sus significados constituyen construcciones gramaticales independientes. De acuerdo con lo establecido en el apartado 2, empleamos el término construcción gramatical desde la gramática de construcciones, esto es, como el emparejamiento convencionalizado de una forma con un significado (vid. Fillmore 1988; Fillmore, Kay y O'Connor 1988; Goldberg 1995, 2006). Como se ha indicado, para algunas de las construcciones no vamos a poder trazar su emergencia en la lengua, por tratarse de estructuras presentes en castellano desde sus orígenes, así para los sentidos de conclusión o finalización, capacidad y logro. Para los valores de posibilidad y de focalización sí vamos a rastrear los cambios que afectan a la forma y al significado de llegar $a+$ INF hasta originar nuevas construcciones gramaticales.

Para probar la emergencia de un nuevo emparejamiento entre una forma y un significado vamos a atender a la evolución que afecta tanto a la semántica como a la morfosintaxis de la perífrasis. El cambio semántico atiende a las modificaciones relacionadas con la semántica, la pragmática y las funciones discursivas de las construcciones gramaticales (apartado 5.1). El cambio formal exige atender a las modificaciones que afectan a la sintaxis, a la morfología y a la fonología de la construcción (apartado 5.2). Este interés equitativo por la forma y el significado permitirá medir 
con mayor exactitud la gradualidad del cambio (para una introducción a la gramática de construcciones diacrónica, vid. Traugott y Trousdale 2013).

\subsection{LOS SIGNIFICADOS QUE MARCAN EL ORIGEN DE LA PERÍFRASIS. LOS SENTIDOS CONCLUSIVOS, DE CAPACIDAD Y DE LOGRO}

Durante el período medieval, llegar $a+$ INF recubre valores de finalización de un proceso previo, de capacidad y de logro (vid. Tabla 2). En lo relativo a la emergencia de estos significados, muy posiblemente esta pueda explicarse como el resultado de evoluciones independientes llegar junto a un infinitivo en contextos sintácticos diferentes. Estaríamos ante un caso similar al que encontramos en el caso de la perífrasis ir $a+\mathrm{INF}$, que, en función de la combinatoria de la construcción, expresa significados de tiempo futuro, de tiempo pasado o de finalización de una secuencia de eventos previa (vid. Garachana Camarero 2019).

\subsubsection{El empleo conclusivo o finalizador de llegar $a+$ inf}

El sentido que consideramos básico de esta perífrasis es el conclusivo. $\mathrm{Si}$ nos centramos en el empleo de llegar como verbo pleno combinado con un verbo en infinitivo, observamos que la distancia respecto del sentido conclusivo de (7) es mínima: cuando llegar se combina con un infinitivo, significa que se alcanza una meta representada por el evento indicado por este infinitivo. Llegar focaliza el significado expresado por el infinitivo, esto es, el sentido deíctico de llegar (que siempre apunta a una meta) se concentra en el infinitivo. Así pues, muy probablemente el punto de partida de la construcción que nos ocupa se sitúe en aquellos contextos en los que, habiéndose omitido cualquier referencia espacial, llegar $a+$ INF se utiliza para introducir el último de una secuencia de eventos que puede quedar explicitada (7a) o no (7b). Así, en (7a), llegó a padecer sitúa el evento de las desgracias y de la miseria que afectan al pueblo al final de una serie: las conquistas sucesivas del rey de Inglaterra condujeron al pueblo a dicha situación. En (7b), en cambio, no sabemos la causa de que el hablante sienta odio hacia el comandante Garrido.

7. a. Por el mismo tiempo Enrico rey de Inglaterra iba adquiriendo y conquistando en el reino de Francia diversas ciudades y castillos, y aquel reino llegó a padecer tanta calamidad y miseria por esta guerra que estuvo muy cerca de sujetarse todo y pasar aquel príncipe el trono principal de su reino a la ciudad de París. (Jerónimo Zurita, Anales de Aragón, siglo XVI, Gradia) 
b. Sabía mucho, tanto que mi conocimiento me congeló en el umbral de la puerta cuando vi bajar desde lo alto de la cuesta a un hombre que de lejos se parecía al comandante Garrido, y había llegado a inspirarme tanto odio, pero tanto miedo a la vez, que no fui capaz de decidir si me gustaba o me repugnaba la idea de que estuviera prisionero tan cerca de mí. (Almudena Grandes, Inés y la alegría, siglo XXI, GraDIA)

Este valor, que tentativamente hemos calificado de conclusivo o finalizador, pues cierra una secuencia de eventos previos, acostumbra a estar teñido de un sentido modal. En efecto, el evento presentado por la perífrasis se ofrece como un argumento más fuerte que los precedentes. De algún modo, la perífrasis introduce un último evento que se sitúa en la posición superior de una escala. En consecuencia, el último evento presentado por la perífrasis suele resultar sorprendente o, incluso, no deseado. En todo caso, lo realmente relevante en el empleo de llegar $a+$ INF con valores conclusivos es que haya una secuencia de eventos que desemboquen en el expresado por la perífrasis. De hecho, a menudo, la construcción aparece como la segunda parte de una oración consecutiva o dentro de una oración temporal que indica un límite o meta temporal:

8. (...) en el juego de la pelota hubieron palabras tan pesadas, que llegaron a romper malamente. (Fray Prudencio de Sandoval, Historia de la vida y hechos del emperador Carlos V, siglo XVII, GRADIA)

9. De tanto pensar en el dichoso cantón, llegó sin duda a figurarse que había estado en él. (Benito Pérez Galdós, Fortunata y Jacinta, siglo XIX, Gradia)

10. Se han dado casos, pero muchos casos, de mujeres unidas por fuerza a un hombre aborrecido, y que le han ido tomando ley poquito a poco hasta llegar a ponerse más tiernas que la manteca. (Benito Pérez Galdós, Fortunata y Jacinta, siglo XIX, GRADIA)

Por lo demás, estos empleos de la perífrasis presentan muy pocas restricciones de empleo. Llegar $a+$ INF se utiliza tanto con tiempos verbales perfectivos como imperfectivos (la Tabla 3 muestra unas oscilaciones entre siglos que no permiten sostener la preferencia de un aspecto sobre el otro) ${ }^{8}$.

\footnotetext{
8 Estos datos parecen poner en entredicho la afirmación de (Fogsgaard 2002, 126), quien considera que "[1]a perífrasis acentúa lo perfectivo, y sin duda se la ve raramente realizada en aspecto imperfectivo. Frente a 17 ejemplos en imperfecto, encontramos 282 en pretérito
} 


\begin{tabular}{|l|r|r|r|r|r|r|r|r|}
\hline & XIII & XIV & XV & XVI & XVII & XVIII & XIX & Xx \\
\hline & & & 100 & & & & & \\
Tiempos & $100 \%$ & & $\%$ & $23,8 \%$ & $70 \%$ & $68 \%$ & $31 \%$ & $50 \%$ \\
imperfectivos & $(2 / 2)$ & ---- & $(2 / 2)$ & $(5 / 21)$ & $(14 / 20)$ & $(17 / 25)$ & $(43 / 139)$ & $(62 / 124)$ \\
\hline & & 100 & & & & & & \\
Tiempos & & $\%$ & & $76,1 \%$ & $30 \%$ & $32 \%$ & $69 \%$ & $50 \%$ \\
perfectivos & ----- & $(1 / 1)$ & ----- & $(16 / 21)$ & $(6 / 20)$ & $(8 / 25)$ & $(96 / 139)$ & $(62 / 124)$ \\
\hline
\end{tabular}

Tabla 3. Distribución de la perfectividad del verbo auxiliar en los valores conclusivos de la perífrasis llegar a + INF (sentidos conclusivos)

En cuanto al tipo de sujeto, aunque estos pueden ser tanto animados como inanimados (Tabla 4), nunca controlan la acción expresada por el infinitivo, sino que, más bien, experimentan dicha acción.

\begin{tabular}{|l|l|r|}
\hline \multirow{2}{*}{ Siglo XIII } & animado & $50 \%(1 / 2)$ \\
\cline { 2 - 3 } & inanimado & $50 \%(1 / 2)$ \\
\hline \multirow{2}{*}{ Siglo XIV } & animado & $100 \%(1 / 1)$ \\
\hline \multirow{3}{*}{ Siglo XVI } & animado & ---- \\
\cline { 2 - 3 } & inanimado & $100 \%(2 / 2)$ \\
\hline \multirow{3}{*}{ Siglo XVII } & animado & $42,85 \%(9 / 21)$ \\
\cline { 2 - 3 } & inanimado & $57,14 \%(12 / 21)$ \\
\hline \multirow{3}{*}{ Siglo XVIII } & animado & $50 \%(10 / 20)$ \\
\cline { 2 - 3 } & inanimado & $50 \%(10 / 20)$ \\
\hline \multirow{2}{*}{ Siglo XIX } & animado & $56 \%(14 / 25)$ \\
\cline { 2 - 3 } & inanimado & $44 \%(11 / 25)$ \\
\hline \multirow{2}{*}{ Siglo XX } & animado & $53,23 \%(74 / 139)$ \\
\cline { 2 - 3 } & inanimado & $63,6 \%(79 / 124)$ \\
\hline
\end{tabular}

Tabla 4. Animacidad del sujeto en los valores conclusivos

indefinido y compuesto". Los datos de la Tabla 3 insisten en nuestra idea de que la perífrasis, considerada globalmente, admite tiempos perfectivos e imperfectivos. 
Por último, llegar $a+$ INF sitúa en la posición del infinitivo verbos que expresan estados, logros, realizaciones o procesos, aunque parece haber una mayor tendencia a utilizar la construcción con verbos que significan logros y estados (vid. Tabla 5). Esta predilección por este tipo de verbos posiblemente pueda ser explicada como resultado de la persistencia semántica del significado etimológico del verbo llegar, que tiene una trascendencia para la combinatoria de la construcción. Llegar, en su acepción como verbo de movimiento, implica un destino, un fin. De ahí que la combinación junto a verbos de logro sea especialmente apropiada. También lo es la aparición junto a verbos que expresan estados a los que puede llegarse (como el verbo ser, por poner solo un caso).

\begin{tabular}{|l|r|}
\hline XIII & $50 \%(1 / 2)$ \\
\hline estado & $50 \%(1 / 2)$ \\
\hline logro & ---- \\
\hline XIV & $100 \%(1 / 1)$ \\
\hline actividad & $100 \%(2 / 2)$ \\
\hline estado & ---- \\
\hline XV \\
\hline estado & \\
\hline proceso & ---- \\
\hline XVI & \\
\hline actividad & $66,6 \%(14 / 21)$ \\
\hline estado & $28,5 \%(6 / 21)$ \\
\hline logro & $4,7 \%(1 / 21)$ \\
\hline realización & \\
\hline XVII & $10 \%(2 / 20)$ \\
\hline actividad & $45 \%(9 / 20)$ \\
\hline estado & $45 \%(9 / 20)$ \\
\hline logro & ---- \\
\hline realización & $24 \%(6 / 25)$ \\
\hline XVIII & $20 \%(12 / 25)$ \\
\hline actividad & \\
\hline estado & \\
\hline logro & \\
\hline
\end{tabular}




\begin{tabular}{|l|r|}
\hline realización & $8 \%(2 / 25)$ \\
\hline XIX & $13,6 \%(19 / 139)$ \\
\hline actividad & $35,25 \%(49 / 139)$ \\
\hline estado & $43,1 \%(60 / 139)$ \\
\hline logro & $7,9 \%(11 / 139)$ \\
\hline realización & \\
\hline XX & $8 \%(10 / 124)$ \\
\hline actividad & $58,8 \%(73 / 124)$ \\
\hline estado & $25,8 \%(32 / 124)$ \\
\hline logro & $7,25 \%(9 / 124)$ \\
\hline realización & \\
\hline
\end{tabular}

Tabla 5. Aktionsart del infinitivo en la perífrasis llegar $a+\mathrm{INF}$ (usos conclusivos)

\subsubsection{Los valores de logro de llegar a + inf}

De manera similar a lo que hemos propuesto para los valores de conclusión o de finalización, la emergencia del significado de logro puede explicarse como el resultado de la combinación del verbo llegar con un infinitivo. Cuando llegar no va acompañado de una indicación de lugar, sino que se combina con un infinitivo que expresa un evento que puede entenderse como un logro, y la combinación de llegar $a+$ INF subcategoriza un argumento externo [+animado, + agentivo, +humano, +volitivo] con capacidad de control, la combinación de llegar con el infinitivo puede reinterpretarse como una estructura especializada en la expresión de la consecución. Si vamos a la Tabla 6, veremos que los sentidos de logro, cuando se documentan, se dan siempre con sujetos animados, que pueden acometer acciones presentadas como metas.

\begin{tabular}{|l|l|r|}
\hline \multirow{3}{*}{ Siglo XIII } & animado & $\begin{array}{r}100 \% \\
(2 / 2)\end{array}$ \\
\cline { 2 - 3 } & inanimado & ---- \\
\hline Siglo XIV & animado & $100 \%(3 / 3)$ \\
\hline \multirow{2}{*}{ Siglo XV } & animado & ---- \\
\cline { 2 - 3 } & inanimado & ---- \\
\hline
\end{tabular}




\begin{tabular}{|l|l|r|}
\hline Siglo XVI & animado & $100 \%(46 / 46)$ \\
\hline \multirow{2}{*}{ Siglo XVII } & inanimado & ---- \\
\cline { 2 - 3 } & animado & $100 \%(63 / 63)$ \\
\hline & inanimado & ---- \\
\hline Siglo XVIII & animado & $100 \%(14 / 14)$ \\
\hline Siglo XIX & inanimado & ---- \\
\hline & animado & $100 \%(98 / 98)$ \\
\hline & inanimado & --- \\
\hline Siglo XX & animado & $100 \%(95 / 95)$ \\
\hline & inanimado & ---- \\
\hline
\end{tabular}

Tabla 6. Animacidad del sujeto en los valores de logro

En (11) y en (12) la perífrasis expresa sendos logros: la victoria (11) y el estatus de emperador (12). Este sentido de logro se ve activado cuando el infinitivo es un verbo que expresa un logro o una realización. Pero es también muy habitual este significado cuando el verbo es ser, como en (12). De alguna manera, podríamos decir con Pountain (1984) que la estructura llegar a ser viene a ser la traducción del inglés become o del francés devenir. Los ejemplos en los que llegar a + INF expresa un logro presentan un objetivo al que se aspira y a menudo se enumeran las acciones que se acometen para alcanzarlo. Así, en (11) incluso se explicita que la victoria era el fin deseado y en (12) se describe la trayectoria anterior del emperador hasta conseguir adquirir esta dignidad. Cuando el estado que se alcanza supone un esfuerzo por parte del sujeto, la inferencia de logro es bastante inmediata.

11. Después, estando en La Cerra a del mes de deciembre, con lo que se publicó de la ida de Reyner a Florencia, todos creían que el rey había llegado a alcanzar la victoria y el fin deseado de la empresa del reino; y túvose gran esperanza de haber muy presto la ciudad de Aversa y que la ciudad de Nápoles no se le podía defender. (Jerónimo Zurita, Anales de Aragón, siglo XVI, GRADIA)

12. Ca primero fue Vozero de demandar los derechos dell Emperador. $\&$ depues fue tribuno de los caualleros. de si subiendo de officio en officio. \& de dignidat en dignidat; puio tanto fasta que llego a seer emperador. \& mantouo ell Jmperio con mucho trabaio. (Alfonso X, Estoria de Espanna, siglo XIII, Gradia) 
Los ejemplos anteriores muestran otro rasgo definitorio de las lecturas de logro, a saber, su identificación con tiempos verbales perfectivos (vid. Tabla 7).

\begin{tabular}{|l|r|r|r|r|r|r|r|r|}
\hline & XIII & XIV & XV & XVI & XVII & XVIII & XIX & XX \\
\hline Tiempos & & & & & & & & \\
imperfectivos & ---- & ---- & --- & --- & --- & --- & -- \\
\hline Tiempos & $100 \%$ & & & $100 \%$ & $100 \%$ & $100 \%$ & $100 \%$ & $100 \%$ \\
perfectivos & $(2 / 2)$ & ----- & ---- & $(40 / 40)$ & $(51 / 51)$ & $(13 / 13)$ & $(93 / 93)$ & $(98 / 98)$ \\
\hline
\end{tabular}

Tabla 7. Distribución de la perfectividad del verbo auxiliar en la perífrasis llegar $a+\mathrm{INF}$ (sentidos de logro)

En lo relativo al tipo de verbo auxiliado, los empleos de llegar a + INF con sentido de consecución muestran una fuerte afinidad por los logros hasta el siglo XVIII (vid. Tabla 8).

\begin{tabular}{|l|r|}
\hline XIII & $100 \%(2 / 2)$ \\
\hline estado & ---- \\
\hline logro & ---- - \\
\hline XIV & $100(3 / 3)$ \\
\hline actividad & \\
\hline estado & ----- \\
\hline XV & ---- \\
\hline estado & \\
\hline proceso & $8,6 \%(4 / 46)$ \\
\hline XVI & $23,9 \%(11 / 46)$ \\
\hline actividad & $60,8 \%(28 / 46)$ \\
\hline estado & $6,5 \%(3 / 46)$ \\
\hline logro & \\
\hline realización & $9,5 \%(6 / 63)$ \\
\hline XVII & $34,9 \%(22 / 63)$ \\
\hline actividad & $47,6 \%(30 / 63)$ \\
\hline estado & $7,9 \%(5 / 63)$ \\
\hline logro &
\end{tabular}




\begin{tabular}{|l|r|}
\hline XVIII & $7,1 \%(1 / 14)$ \\
\hline actividad & $57,1 \%(8 / 14)$ \\
\hline estado & $35,7 \%(5 / 14)$ \\
\hline logro & \\
\hline realización & \\
\hline XIX & $12 \%(12 / 98)$ \\
\hline actividad & $43,8 \%(43 / 98)$ \\
\hline estado & $29,6 \%(29 / 98)$ \\
\hline logro & $14 \%(14 / 98)$ \\
\hline realización & \\
\hline XX & $15,7 \%(15 / 95)$ \\
\hline actividad & $46,3 \%(44 / 95)$ \\
\hline estado & $26 \%(25 / 95)$ \\
\hline logro & $11,57 \%(11 / 95)$ \\
\hline realización & \\
\hline
\end{tabular}

Tabla 8. Aktionsart del infinitivo en la perífrasis llegar $a+\mathrm{INF}$ (sentidos de logro)

Sin embargo, como también sucede con los valores de capacidad, se detecta una marcada tendencia al empleo junto a verbos estativos en los siglos XIX y xx. Esta tendencia tiene que ponerse directamente en conexión con el aumento de frecuencia que el verbo ser experimenta en el siglo xx, que afectó de manera particular a las lecturas de logro y de capacidad, aunque también a las de finalización.

\begin{tabular}{|l|r|r|r|r|r|r|r|r|}
\hline & XIII & XIV & XV & XVI & XVII & XVIII & XIX & XX \\
\hline ser & $75 \%$ & $100 \%$ & --- & $11,1 \%$ & $6,74 \%$ & $14,47 \%$ & $12,59 \%$ & $21,56 \%$ \\
& $(3 / 4)$ & $(4 / 4)$ & & $(14 / 126)$ & $(17 / 163)$ & $(11 / 76)$ & $(66 / 524)$ & $(110 / 510)$ \\
\hline
\end{tabular}

Tabla 9. Empleo del verbo ser en la perífrasis llegar $a+\mathrm{INF}$

De alguna manera, este aumento remarcable de la construcción llegar a ser podría ser indicativa de una construccionalización léxica de la perífrasis (en la línea de lo señalado en el capítulo de Alba-Salas $\rightarrow$ este volumen). Concretamente, llegar $a+$ sER se iría consolidando, desde los orígenes del idioma, para cubrir el vacío léxico que Pountain señaló para el español. Esta es, sin embargo, una cuestión a la que no podemos dedicar más atención por cuestiones de espacio. 


\subsubsection{La expresión de la capacidad con llegar a + inf}

Cuando la combinación llegar a + INF implica un verbo conjugado en un tiempo imperfectivo y un sujeto animado, volitivo o no, se activa la presuposición de que la construcción expresa la capacidad del sujeto para realizar una acción. Esto resulta particularmente visible en contextos negados (vid. Rosemeyer y Garachana 2019). Es decir, cuando el verbo auxiliar está conjugado en un tiempo imperfectivo, ya no se afirma que este sujeto consiga la meta que se trazó, sino que se hace alguna afirmación relacionada con su capacidad para conseguirlo. Así, en (13) la perífrasis puede reformularse

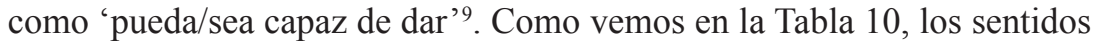
de capacidad de llegar $a+$ INF se corresponden a estructuras en las que el verbo auxiliar está conjugado en un tiempo imperfectivo.

13. Ya sé que por muy buen ejemplo que llegue a dar uno, los demás siempre tienen a la vista demasiados malos ejemplos que imitar. (Fernando Savater, Ética para Amador, siglo xx, GRADIA)

\begin{tabular}{|l|r|r|r|r|r|r|r|r|}
\hline & XIII & XIV & XV & XVI & XVII & XVIII & XIX & XX \\
\hline Tiempos & $100 \%$ & $100 \%$ & $100 \%$ & $100 \%$ & $100 \%$ & $100 \%$ & $100 \%$ & $100 \%$ \\
imperfectivos & $(2 / 2)$ & $(3 / 3)$ & $(1 / 1)$ & $(20 / 20)$ & $(42 / 42)$ & $(11 / 11)$ & $(76 / 76)$ & $(80 / 80)$ \\
\hline $\begin{array}{l}\text { Tiempos } \\
\text { perfectivos }\end{array}$ & & & & & & & & \\
\hline
\end{tabular}

Tabla 10. Distribución de la perfectividad del verbo auxiliar en los valores de capacidad la perífrasis llegar $a+$ INF

La afinidad que se aprecia entre los valores de logro y de capacidad hace que, incluso si las diferencias formales son suficientemente remarcables (la exclusión de los tiempos perfectivos para los significados de capacidad y de los imperfectivos para los de logro), presenten también una remarcable proximidad formal que se puede apreciar en la afinidad que manifiestan con los verbos que expresan logros. Además, como en el caso de las lecturas de consecución o logro, las de capacidad muestran una clara tendencia histórica hacia los verbos que expresan estados, de manera particular hacia ser. A diferencia de las lecturas de logro, el decantamiento hacia los verbos estativos es propio del siglo XX (vid. Tabla 11).

\footnotetext{
9 Estos ejemplos permiten ver que la propuesta de Pountain para considerar que llegar a ser es una especie de correlato interlingüístico del inglés become o del francés devenir, solo puede aceptarse para algunos de los valores de la perífrasis.
} 


\begin{tabular}{|l|r|}
\hline XIII & \\
\hline estado & $50 \%(1 / 2)$ \\
\hline logro & $50 \%(1 / 2)$ \\
\hline XIV & ----- \\
\hline actividad & ---- \\
\hline estado & \\
\hline XV & ---- \\
\hline estado & $100 \%(1 / 1)$ \\
\hline proceso & \\
\hline XVI & $13,3 \%(2 / 15)$ \\
\hline actividad & $13,3 \%(2 / 15)$ \\
\hline estado & $66,6 \%(10 / 15)$ \\
\hline logro & $6,6 \%(1 / 15)$ \\
\hline realización & \\
\hline XVII & $29,4 \%(10 / 34)$ \\
\hline actividad & $26,4 \%(9 / 34)$ \\
\hline estado & $35,2 \%(12 / 34)$ \\
\hline logro & $8,8 \%(3 / 34)$ \\
\hline realización & \\
\hline XVIII & $9 \%(1 / 11)$ \\
\hline actividad & $26,4 \%(23 / 87)$ \\
\hline estado & $42,5 \%(37 / 87)$ \\
\hline logro & $23,6 \%(18 / 76)$ \\
\hline realización & $42,1 \%(32 / 76)$ \\
\hline XIX & $15,7 \%(12 / 76)$ \\
\hline actividad & $9(1 / 11)$ \\
\hline estado & \\
\hline logro & \\
\hline realización & \\
\hline XX & \\
\hline actividad & \\
\hline estado & \\
\hline & \\
\hline
\end{tabular}




\begin{tabular}{|l|r|}
\hline logro & $24,1 \%(21 / 87)$ \\
\hline realización & $6,8 \%(6 / 87)$ \\
\hline
\end{tabular}

Tabla 11. Aktionsart del infinitivo en la perífrasis llegar a + INF (valores de capacidad)

En lo relativo a los sujetos gramaticales, las lecturas de logro y de capacidad demandan sujetos [+animados] (vid. Tabla 12). Ahora bien, solo los logros exigen sujetos agentivos; la noción de capacidad neutraliza tal exigencia. Así, en este ámbito es posible encontrar tanto sujetos agentivos (13) como no agentivos (14). Así pues, podemos postular que los valores de logro y de capacidad conforman construcciones gramaticales diferentes, aunque conectadas entre sí.

13. Tampoco llegaría nunca a alegrarme tanto de no tenerlo cerca como el 16 de agosto, cuando la fiesta terminó. (Almudena Grandes, Inés y la alegría, siglo XXI, GRADIA)

\begin{tabular}{|l|l|}
\hline XIII & \\
\hline animado & $\begin{array}{l}100 \% \\
(2 / 2)\end{array}$ \\
\hline inanimado & ---- \\
\hline XIV & \\
\hline animado & ---- \\
\hline XV & \\
\hline animado & $100 \%(1 / 1)$ \\
\hline inanimado & ---- \\
\hline XVI & \\
\hline animado & $100 \%(15 / 15)$ \\
\hline inanimado & ---- \\
\hline XVII & \\
\hline animado & $100 \%(34 / 34)$ \\
\hline inanimado & ---- \\
\hline XVIII & \\
\hline animado & $100 \%(11 / 11)$ \\
\hline
\end{tabular}




\begin{tabular}{|l|l|}
\hline inanimado & ---- \\
\hline XIX & \\
\hline animado & $100 \%(76 / 76)$ \\
\hline inanimado & ---- \\
\hline XX & \\
\hline animado & $100 \%(88 / 88)$ \\
\hline inanimado & ---- \\
\hline
\end{tabular}

Tabla 12. Animacidad del sujeto en los valores de capacidad

\subsubsection{Una construcción etimológica, tres construccionalizaciones}

De acuerdo con lo que hemos presentado en los apartados anteriores, la construcción etimológica [[llegar $\left[_{\text {sp locativo }}\right.$ a $\left.\mathrm{SN}\right]+\left[_{\mathrm{sp} \text { final }}\right.$ a INF $]$ habría experimentado tres procesos de cambio que llevan a la configuración de tres estructuras formalmente conectadas entre sí. Una vez eliminada la indicación de lugar, la focalización de llegar sobre el infinitivo se plasma en tres construcciones diferentes, a saber, la conclusiva o finalizadora de una serie de acciones previas, la consecutiva o de logro y la de modalidad dinámica o capacidad. En los tres casos, podemos hablar de un cambio por construccionalización, ya que una nueva forma (la que vincula llegar a un infinitivo directamente) se asocia a nuevos significados (conclusivo, de logro y de capacidad). Además, la forma de cada uno de estos significados presenta diferencias que las singularizan, por más que en los tres casos los verbos auxiliares suelan ser logros o estados. Así, el sentido conclusivo supone la presencia de sujetos [ \pm animados, - volitivos], verbo auxiliar conjugado en tiempos $[ \pm$ perfectivos]. En cambio, los valores de logro implican sujetos [+animados, +volitivos] y el auxiliar, en tiempo [+perfectivo]. Por último, los valores de capacidad presentan sujetos [ + animados, \pm volitivos] y el verbo auxiliar conjugado en tiempo [-perfectivo]. De manera esquemática podemos representar esta triple construccionalización de la siguiente manera: 


\section{Construcción etimológica}

\begin{tabular}{|l|}
\hline FORMA \\
\hline$\left[\right.$ llegar $\left[{ }_{\text {sp locativa }}\right.$ a SN $]+\left[_{\text {sp final }}\right.$ a INF $]$ \\
Sujeto $[+$ animado, + volitivo $]$ \\
Auxiliar $[ \pm$ perfectivo $]$ \\
Auxiliado [estados, procesos, realizaciones, lo- \\
gros $]$
\end{tabular}

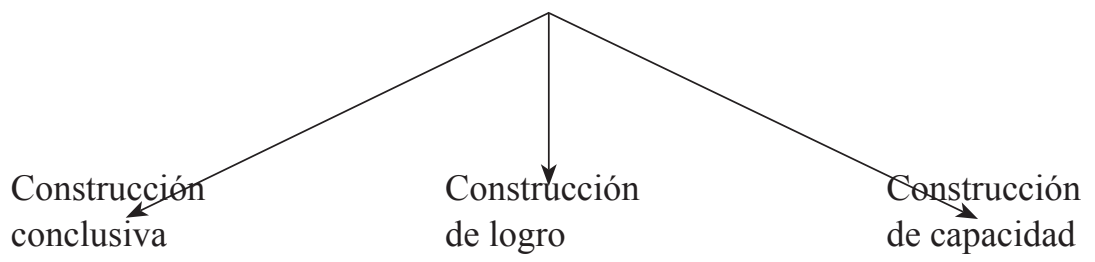

\begin{tabular}{|c|c|}
\hline FORMA & \\
\hline \multirow[b]{2}{*}{\begin{tabular}{|l|} 
[llegar a INF $]$ \\
Suj $[ \pm$ animado, \\
$\quad$ - volitivo $]$ \\
Aux, $[ \pm$ perfectivo $]$ \\
Auxiliado \\
(principalmente) \\
[estados, logros $]$ \\
\end{tabular}} & FORMA \\
\hline & \multirow[t]{2}{*}{\begin{tabular}{|l} 
[llegar a INF $]]$ \\
Suj [+animado, \\
$\quad$ +volitivo] \\
Aux, [+ perfectivo $]$ \\
Auxiliado \\
(principalmente) \\
[estados, logros $]$ \\
\end{tabular}} \\
\hline SIGNIFICADO & \\
\hline \multirow{2}{*}{$\begin{array}{l}\text { Final de una serie de } \\
\text { acciones previas }\end{array}$} & SIGNIFICADO \\
\hline & Logro \\
\hline
\end{tabular}

\begin{tabular}{|l|}
\hline FORMA \\
\hline$\left[\begin{array}{l}\text { [llegar a INF] } \\
\text { Suj [+animado, } \\
\quad \pm \text { volitivo] } \\
\text { Aux, [- perfectivo] } \\
\text { Auxiliado } \\
\text { (principalmente) } \\
\text { [estados, logros] }\end{array}\right.$ \\
\hline SIGNIFICADO \\
\hline Capacidad \\
\hline
\end{tabular}




\subsection{El DesarRollo de NUEVAS CONSTRUCCIONES GRAMATICALES}

La lengua clásica supone la consolidación de llegar $a+$ INF en la lengua castellana, así como la aparición de los valores de posibilidad y focalización. Los primeros son una derivación del significado de capacidad; los segundos, una extensión de los valores conclusivos. En este apartado vamos a tratar de probar que el desarrollo de estos nuevos valores puede postularse como nuevas uniones de formas nuevas con nuevos significados, $\mathrm{y}$, por lo tanto, como nuevas construccionalizaciones. Vamos a empezar por estudiar la emergencia de los valores focalizadores, documentados en nuestro corpus desde el siglo Xvi. A continuación, nos vamos a ocupar de los sentidos de posibilidad, recogidos desde el siglo XVII (vid. Tabla 2$)^{10}$.

\subsubsection{Los sentidos focalizadores}

En la introducción, hemos indicado que bajo la denominación de sentidos focalizadores incluíamos tanto aquellos casos en los que la perífrasis tiene un sentido focalizador fuerte, casi sinónimo de 'incluso', como los que resultan más atenuados. En lo relativo a su origen, cabe plantear la hipótesis de que el sentido conclusivo de la perífrasis, que permite que esta se emplee para señalar el último elemento de una serie previa, explica que esta desarrolle valores escalares que denotan sentidos ponderativos o intensificativos. En efecto, al introducir el último elemento de una serie, al cerrar dicha serie introduciendo el argumento más relevante de la argumentación, llegar a + INF puede constituirse en sinónimo de incluso. Así, el ejemplo de (15a)

10 En la diferenciación entre cambio construccional y construccionalización, seguimos la propuesta de Traugott y Trousdale (2013), diferente de las de Smirnova (2015), Hilpert $(2013,2018)$ o Boye y Harder (2012). Así consideramos que el cambio construccional es una modificación de uno de los dos polos que conforman las construcciones gramaticales, esto es, puede consistir en una evolución del significado o de la forma. El cambio construccional, pues, supone cambios que pueden afectar o bien a la semántica de la construcción (por ejemplo, ir a + INF: espacio > futuro o pasado), o bien a su morfofonología (te voy a dar > [tißjaðár]; cf. Garachana Camarero 2019) o bien a su patrón de colocaciones (por ejemplo, la expansión contextual de ir $a+$ INF con valor prospectivo permite a esta construcción emplearse no solo junto a infinitivos que denotan actividades, sino, incluso estados: va a ser divertido). En cambio, la construccionalización supone un nuevo emparejamiento de forma y significado, esto es, el surgimiento de un nuevo signo lingüístico. Por lo tanto, la construccionalización significa la creación de nuevas construcciones gramaticales, de modo que, stricto sensu, el cambio gramatical se produce en ella. El cambio construccional o bien es un estadio previo que conduce a la emergencia de un nuevo emparejamiento de una forma y de un significado, o bien se produce después de dicha emergencia, propiciando ulteriores cambios gramaticales (la posgramaticalización). 
encierra un sentido intensificador (yo me cré incluso) que se ve corroborado por el contexto que sigue inmediatamente (me lo tragué). A partir del siglo XVIII, la perífrasis puede aparecer acompañada de operadores escalares como incluso, hasta o aun (15b, c y d), que parecen sugerir que el valor focalizador requiera un refuerzo.

15. a. -Pero también le diré a usted que yo no contaba con volverle a ver... Pensé que no se acordaba de mí. Yo me llegué a creer que podría ser buena y honrada... me lo tragué. (Benito Pérez Galdós, Fortunata y Jacinta, siglo XIX, GRADIA)

b. Lo razonable en tales circunstancias era ceder, para impedir que los agresores perdiesen los estribos y causaran serios daños o incluso llegaran a matar. (Eric Hobsbawm, Historia del siglo XX, siglo XX, GRADIA)

c. Nadie puede pecar, decían, mientras el espíritu de Dios está en nosotros. Y aun llegaban a creer que cada uno de ellos era Cristo y el Espíritu Santo. (Menéndez Pelayo, Historia de los heterodoxos españoles, siglo XIX, GRADIA)

d. La pobre Carmen reniega de su amor como si fuera una infamia, olvida el precio de la invasión de Arán antes que nadie, y hasta llega a creer que ha escapado, sana y salva, del campo de minas que ella misma ha sembrado, el rosario de bombas que le estallará debajo de los pies cuando menos se lo espere. (Almudena Grandes, Inés y la alegría, siglo XXI, GRADIA)

Resultan interesantes ejemplos como el de (16), en el que hasta aparece entre los formantes de la perífrasis (falta la preposición $a$ ), lo que contribuye a resaltar más el sentido focalizador de esta.

16. Cuando Juan se hallaba en esta situación, llegaba hasta desear permanecer en ella; aún más, llegaba a creer que seguiría. (Benito Pérez Galdós, Fortunata y Jacinta, siglo XIX, GRADIA)

En este punto, creemos que conviene hacer un par de consideraciones. En primer lugar, ejemplos como el de (16) ponen de manifiesto que la interpolación de elementos entre los formantes de la perífrasis no puede ser considerada sin más un criterio para su inclusión o exclusión de la categoría. Los límites entre los formantes de las perífrasis son límites de palabra, no límites morfológicos, de manera que la posibilidad de la intercalación de elementos es posible (Garachana Camarero 2017b). En segundo lugar, y en clara relación con la primera consideración, este tipo de interpolaciones, que 
no se limitan a elementos afines al significado de la perífrasis como en el caso de (16), tienen que ponerse en relación necesariamente con el empleo de estas construcciones multiverbales como elementos focalizadores. En efecto, al situar entre los formantes de la perífrasis un elemento léxico o gramatical, se coloca en el centro de la predicación una información que, ineludiblemente, queda focalizada. De hecho, el español llegó a gramaticalizar con valor focalizador una forma de futuro de indicativo que interpolaba entre sus formantes elementos gramaticales, especialmente pronombres personales. Me refiero al empleo de las formas de futuro de indicativo que intercalaban entre sus formantes un pronombre mesoclítico (vid. Bouzouita 2012; Medina Urrea y Company Company 1999).

Junto a casos de focalización fuerte como los anteriores, la perífrasis llegar $a+$ INF se documenta en enunciados como el de (17), donde la línea divisoria entre la forma simple y la perifrástica es muy tenue (vid. Gómez Torrego 1999: 3385). Estos empleos de la perífrasis casi redundantes constituyen formas de focalización no intensiva y suelen añadir al enunciado una idea de algo no esperado o no deseado. Se trata de ejemplos en los que llegar $a+$ INF simplemente sirve para perspectivizar el evento recogido en el infinitivo, poniendo de realce el hecho de que dicho evento tiene lugar tras una sucesión previa de eventos, que puede quedar explicitada o no. Así pues, lo más interesante de estos usos de focalización atenuada es la inferencia que se desencadena, pues al emplearse llegar $a+$ INF se entiende que se llega al evento contenido en el infinitivo tras un período previo en el que este no se daba. En el siguiente fragmento textual, por ejemplo, llegaría a abrumar resalta el peso que la muchacha sentiría, tras un período previo en el que dicho agobio se fue gestando.

17. Cuando ingresó en el Partido, una muchacha entonces, casi una niña, jamás se atrevió a imaginar la enormidad de la carga que algún día llegaría a abrumar sus hombros, que anularía su imaginación y estremecería su conciencia. (Almudena Grandes, Inés y la alegría, siglo XXI, GRADIA)

Algo similar se observa en (18): llegué a contarle no presenta una diferencia semántica remarcable si la comparamos con conté, más allá del hecho de que con la perífrasis llegué tiene un sentido focalizador o intensificador del evento expresado por el infinitivo similar al que tiene ir en enunciados como Fue a llover el día de mi boda (Bravo Martín 2014; Garachana Camarero 2019). Así, la diferencia entre nunca le conté a mi cuñada y nunca llegué a contarle a mi cuñada radica en que con la perífrasis se mantiene una idea de secuencialización inexistente en la forma simple: llegué a contarle implica 
un transcurso de tiempo que no concluye con la confesión de que quizá la cuñada tuviera razón.

18. Ninguno de nosotros volvió a ver en Francia a la secretaria general del PCE. Por eso, nunca llegué a contarle a mi cuñada que quizás tuviera razón, que Dolores, sin dejar jamás de ser ella misma, grande como ninguna, inmortal como muy pocas, podría haber sido al mismo tiempo una pobre mujer. (Almudena Grandes, Inés y la alegría, siglo XXI, GRADIA)

La idea de recorrido se ve todavía mejor en el siguiente ejemplo en el que la perífrasis tiene ese valor de focalización tenue del que venimos hablando: con la expresión nunca llegamos a dejarlo del todo se marca una trayectoria que, al estar la perífrasis negada, no presenta un final. De ahí que la perífrasis se emplee para marcar lo no prototípico de la situación en la que el sujeto del que se está hablando simultanea dos relaciones sentimentales.

19. CRI: $[<]<$ yo $>/$ salí //\$ con él // \$ luego lo dejamos // luego conoció a Ilsa //\$ pero nunca lo llegamos a dejar del todo / entonces ahora está con las dos. (C-ORAL, SIGLO XX, GRADIA)

Los sentidos focalizadores mantienen presente la noción de recorrido que caracteriza al verbo llegar, si bien se trata de un recorrido metafórico que se concentra en la expresión del evento indicado por el infinitivo. Los significados focalizadores suponen que la idea de finalización ya no se entiende en términos de acciones que terminan para dar paso a una nueva acción, sino en términos escalares: lo que se sitúa en último lugar es una situación que se creía difícil o imposible. Ahí radica el cambio semántico que ha experimentado la construcción.

En el plano formal, la construcción focalizadora presenta ciertos rasgos particularizantes, que permiten proponer que una nueva construcción gramatical ha aparecido. En efecto, si atendemos a la sintaxis de la construcción, observamos que, a diferencia de los valores conclusivos, los focalizadores no muestran en la lengua una afinidad tan estrecha por los infinitivos que expresan logros y estados: la historia de los sentidos focalizadores también da cabida a las actividades en una proporción significativa (vid. Tabla 13).

\begin{tabular}{|l|l|}
\hline XVI & \\
\hline actividad & $27,2 \%(12 / 44)$ \\
\hline estado & $38,6 \%(17 / 44)$ \\
\hline
\end{tabular}




\begin{tabular}{|l|r|}
\hline logro & $45,4 \%(10 / 44)$ \\
\hline realización & $11,3 \%(5 / 44)$ \\
\hline XVII & \\
\hline actividad & $15,8 \%(14 / 44)$ \\
\hline estado & $45,4 \%(7 / 44)$ \\
\hline logro & $6,8 \%(3 / 44)$ \\
\hline realización & \\
\hline XVIII & $41,6 \%(10 / 24)$ \\
\hline actividad & $16,6 \%(4 / 24)$ \\
\hline estado & $25 \%(6 / 24)$ \\
\hline logro & $16,6 \%(4 / 24)$ \\
\hline realización & \\
\hline XIX & $32,8 \%(64 / 195)$ \\
\hline actividad & $29,2 \%(57 / 195)$ \\
\hline estado & $25,6 \%(50 / 195)$ \\
\hline logro & $12,3 \%(24 / 195)$ \\
\hline realización & \\
\hline XX & $14,6 \%(29 / 198)$ \\
\hline actividad & $43,4 \%(86 / 198)$ \\
\hline estado & $26,2 \%(52 / 198)$ \\
\hline logro & $15,6 \%(31 / 198)$ \\
\hline realización & \\
\hline
\end{tabular}

Tabla 13. Aktionsart del infinitivo en la perífrasis llegar $a+\mathrm{INF}$ (sentidos focalizadores)

En lo que concierne a la perfectividad del verbo auxiliar, diremos que, frente a las oscilaciones que se observan en los valores conclusivos respecto del tiempo en que se conjuga el verbo auxiliar, que no permiten afirmar la preeminencia de unos tiempos sobre otros de manera taxativa (vid. apdo. 5.1.1.), las lecturas focalizadoras muestran mayor regularidad de empleo en ambos sentidos que solo se rompe en el siglo xx cuando destacan los tiempos imperfectivos (Tabla 14). 


\begin{tabular}{|l|r|r|r|r|r|}
\hline & XVI & XVII & XVIII & XIX & XX \\
\hline Tiempos & $45,4 \%$ & $45,4 \%$ & $37,5 \%$ & $44,10 \%$ & $66,6 \%$ \\
imperfectivos & $(20 / 44)$ & $(20 / 44)$ & $(9 / 24)$ & $(86 / 195)$ & $(132 / 198)$ \\
\hline Tiempos & $54,5 \%$ & $54,5 \%$ & $62,5 \%$ & $55,9 \%$ & $33,3 \%$ \\
imperfectivos & $(24 / 44)$ & $(24 / 44$ & $(15 / 24)$ & $(109 / 195)$ & $(66 / 198)$ \\
\hline
\end{tabular}

Tabla 14. Distribución de la perfectividad del verbo auxiliar en los valores focalizadores de la perífrasis llegar $a+\mathrm{INF}$

También en la línea de las diferencias, hay que subrayar que, la focalización se decanta de manera muy marcada por los sujetos animados (vid. Tabla 15), algo que no se da con los valores conclusivos.

\begin{tabular}{|l|r|}
\hline XVI & $75 \% \%(33 / 44)$ \\
\hline animado & $25 \%(11 / 44)$ \\
\hline inanimado & \\
\hline XVII & $72,7 \%(32 / 44)$ \\
\hline animado & $27,3 \%(12 / 44)$ \\
\hline inanimado & \\
\hline XVIII & $62,5 \%(15 / 24)$ \\
\hline animado & $37,5 \%(9 / 24)$ \\
\hline inanimado & \\
\hline XIX & $83,6 \%(163 / 195)$ \\
\hline animado & $16,4 \%(32 / 195)$ \\
\hline inanimado & \\
\hline XX & $56 \%(111 / 198)$ \\
\hline animado & $44 \%(87 / 198)$ \\
\hline inanimado & \\
\hline
\end{tabular}

Tabla 15. Animacidad del sujeto en los valores focalizadores

\subsubsection{La expresión de la posibilidad}

Los valores de posibilidad, ejemplificados en (20), muestran un cambio semántico, nacido en los empleos de capacidad de la construcción. 
20. descubierta un instante la extremidad de su rostro, por la cual parecía poderse deducir fundamentalmente la hermosura del resto que no se llegaba a ver; levantándose alguna vez un poco más el antifaz, llegaba a descubrirse cerca de la boca la huella de una fugitiva y vaga sonrisa. (Mariano José de Larra, El doncel de don Enrique el Valiente, siglo XIX, GRADIA)

La evolución desde la noción de capacidad (posibilidad dinámica) hasta la de posibilidad (posibilidad epistémica) conforma una trayectoria evolutiva bien conocida en la historia de las lenguas (por ejemplo, Sweetser 1991). El cambio semántico parte de la noción de capacidad misma. En efecto, de la idea de capacidad de una persona para llevar a cabo una acción se infiere que dicha acción puede realizarse. Esto es, en el significado de capacidad se infiere la noción de posibilidad, que se activa cuando el sujeto no es una entidad animada específica que puede realizar dicha acción. En estos casos, lo que se expresa es la posibilidad de que un evento pueda llegar a tener lugar. De hecho, disponemos de contextos puente en los que el carácter impersonal de la construcción no elimina una lectura de capacidad, pero activa una interpretación de la construcción en términos de posibilidad. Este es el caso de los ejemplos de (21), que pueden entenderse como la expresión de la capacidad ("hasta poder ver a mi hermana"-"hasta poder verse con Ataliba"), o como la expresión de la posibilidad ("hasta que sea posible ver a mi hermana"-"hasta que fuese posible verse con Ataliba").

21. a. (...) siendo dios serbido acabaremos con esta nabegazion que la de la mar del sur y la postrera y alabada restara solo quinientas leguas de tierra asta llegar a ber a mi hermana. (Marta Fernández Alcaide. Cartas privadas de españoles en el Nuevo Mundo, siglo XVI, GRADIA)

b. Antes que llegase a verse con Atabaliba, le vinieron embajadores de Huascar, pidiéndole paz y amistad con su hermano. (Fray Prudencio de Sandoval, Historia de la vida y hechos del emperador Carlos V, siglo XVII, GRADIA)

Esta evolución semántica tiene una contrapartida sintáctica. Así, pese a que el tipo de verbo auxiliado pertenece sobre todo a la clase de los estados y de los logros (Tabla 16), como en las lecturas de capacidad; y pese a que el tiempo en que se conjuga el verbo auxiliar también se concentra en los tiempos imperfectivos, siguiendo la estela de las lecturas de capacidad (Tabla 17); la construcción epistémica presenta un cambio tangencial respecto de la estructura de capacidad. Este cambio consiste en que los sujetos son siempre inanimados, tal y como se puede ver en la Tabla 18. Estas características sintácticas de la construcción permiten afirmar que 
una nueva construccionalización afectó a la perífrasis llegar $a+$ INF a partir del siglo XVII.

\begin{tabular}{|l|r|}
\hline XVII & ---- \\
\hline actividad & $50 \%(1 / 2)$ \\
\hline estado & $50 \%(1 / 2)$ \\
\hline logro & --- \\
\hline realización & \\
\hline XVIII & ---- \\
\hline actividad & $50 \%(1 / 2)$ \\
\hline estado & $50 \%(1 / 2)$ \\
\hline logro & ---- \\
\hline realización & \\
\hline XIX & $25 \%(4 / 16)$ \\
\hline actividad & $25 \%(4 / 16)$ \\
\hline estado & $50 \%(8 / 16)$ \\
\hline logro & ---- \\
\hline realización & \\
\hline XX & \\
\hline actividad & $16,6 \%(1 / 6)$ \\
\hline estado & $66,6 \%(4 / 6)$ \\
\hline logro & $16,6 \%(1 / 6)$ \\
\hline realización & ---- \\
\hline
\end{tabular}

Tabla 16. Aktionsart del infinitivo en la perífrasis llegar $a+\mathrm{INF}$ (valores de posibilidad)

\begin{tabular}{|l|r|r|r|r|}
\hline & XVII & XVIII & XIX & XX \\
\hline Tiempos & $100 \%$ & $100 \%$ & $61,1 \%$ & $100 \%$ \\
imperfectivos & $(2 / 2)$ & $(2 / 2)$ & $(11 / 18)$ & $(6 / 6)$ \\
\hline Tiempos & & & $38,8 \%$ & \\
imperfectivos & ---- & ---- & $(7 / 18)$ & ---- \\
\hline
\end{tabular}

Tabla 17. Distribución de la perfectividad del verbo auxiliar en los valores de posibilidad de la perífrasis llegar $a+\mathrm{INF}$ 


\begin{tabular}{|l|r|}
\hline XVII & $100 \%(2 / 2)$ \\
\hline animado & --- \\
\hline inanimado & \\
\hline XVIII & $100 \%(2 / 2)$ \\
\hline animado & \\
\hline inanimado & \\
\hline XIX & \\
\hline animado & $6,25 \%(1 / 16)$ \\
\hline impersonal & ---- \\
\hline inanimado & $93,75 \%(15 / 16)$ \\
\hline XX & \\
\hline animado & $100 \%(5 / 5)$ \\
\hline inanimado & \\
\hline
\end{tabular}

Tabla 18. Animacidad del sujeto en los valores de posibilidad

\section{LOS CONTEXTOS SINTÁCTICOS DE LLEGAR A + INF EN EL TRANSCURSO DE LOS SIGLOS}

Analizar la trayectoria histórica de la perífrasis llegar a + INF no solo resulta dificultosa por la variedad de significados y de subesquemas sintácticos que lleva asociada, sino también porque su empleo ha quedado a menudo vinculado a contextos sintácticos específicos que han terminado siendo caracterizadores de la construcción misma. A estos contextos sintácticos les dedicamos los apartados que siguen.

\subsection{LA NEGACIÓN}

Resulta interesante resaltar el hecho de que todos los valores de la perífrasis aparecen con relativa frecuencia en contextos negativos. Como suele suceder con las perífrasis, la negación puede afectar el significado de la construcción verbal, de modo que llegar $a+$ INF puede significar también fracaso a la hora 
de alcanzar un evento (22a), la frustración de no alcanzar un logro (10b), o la falta de capacidad para ello (22c). También se recogen lecturas que expresan la imposibilidad de que un hecho determinado se cumpla (22d) y, por último, encontramos la perífrasis en contextos focales atenuados (22e).

22. a. Un par de minutos más tarde, cuando volvimos a verlos, la mujer se había tapado la cara con las manos, y él, sin llegar a alinearse con el umbral, para no servir de blanco a los tiradores de la iglesia, nos miró y señaló a la torre con un dedo. (Almudena Grandes, Inés y la alegría, siglo XXI, GRADIA)

b. Pero nunca llegué a comprender el afán que por asistir al baile había manifestado tantos días seguidos don Cleto. (Mariano José de Larra, El mundo todo es máscaras. Todo el año es carnaval, siglo XIX, Gradia)

c. Calcula mal, porque Paco, que ya ama a otra mujer, nunca llegará a amarla tanto, tan tierna, $\tan$ apasionada, tan incondicionalmente, como en las largas y tenebrosas, interminables sesiones de su desgracia. (Almudena Grandes, Inés y la alegría, siglo XXI, GRADIA)

d. [...] algunos retazos de la tragedia Polixena, que nunca llegó a representarse por falta de actores [...]. (Menéndez Pelayo, Historia de los heterodoxos españoles, siglo XIX, GRADIA)

f. La respuesta de Carrillo no es el único dato relevante, y asombroso al mismo tiempo, de aquella reunión sobre la que Manuel Gimeno nunca llega a escribir, pero sí cuenta en algunas entrevistas. (Almudena Grandes, Inés y la alegría, siglo XXI, GRADIA)

Cuando los sentidos focalizadores fuertes aparecen negados, la lectura que se activa puede hacer equivalente la construcción al operador ni siquiera (23) o puede activarse una interpretación afirmativa. Así, en (24) la negación no afecta a llegar a decir, sino que, en tanto que interrogación retórica, se trata de un caso de negación pragmática que activa una lectura afirmativa del enunciado (Garachana Camarero 2008).

23. Algunas ni eso, no han llegado a tener la regla. (Jaime Prats, "Reserva de paternidad para niños con cáncer", El País. 24.10.2014, siglo XXI, GRADIA)

24. Yo no entiendo a Juan, ¿no ha llegado a decirme que le había agredido verbalmente? 
Si atendemos a los empleos afirmativos $v s$. los usos negativos de llegar $a+$ INF, lo primero que llama la atención es la progresiva consolidación del patrón negativo en la historia de la perífrasis (vid. Tabla 18). Así, pasamos de unos estadios en los que la negación no intervenía en la construcción perifrástica que nos ocupa a otros en los que más del $27 \%$ del total de empleos de la construcción en el siglo xx corresponden a estructuras negativas.

\begin{tabular}{|c|c|c|c|}
\hline Siglo & afirmativa & $\begin{array}{r}\text { Negación ante } \\
\text { infinitivo }\end{array}$ & negativa \\
\hline XIII & $100 \%(6 / 6)$ & ---- & ---- \\
\hline XIV & $100 \%(4 / 4)$ & ---- & ---- \\
\hline $\mathrm{XV}$ & $100 \%(3 / 3)$ & ---- & ---- \\
\hline XVI & $93,6 \%(118 / 126)$ & ---- & $6,3 \%(8 / 126)$ \\
\hline XVII & $90,68 \%(146 / 161)$ & ---- & $9,31 \%(15 / 161)$ \\
\hline XVIII & $88,46 \%(69 / 78)$ & ---- & $11,53 \%(9 / 78)$ \\
\hline XIX & $85,1 \%(446 / 524)$ & $0,19 \%(1 / 524)$ & $19,69 \%(77 / 524)$ \\
\hline $\mathrm{xx}$ & $72,35 \%(369 / 510)$ & ---- & $27,64 \%(141 / 510)$ \\
\hline
\end{tabular}

Tabla 18. Polaridad y empleo de llegar $a+$ INF

$\mathrm{Si}$ atendemos a los diferentes significados, los que parecen concentrar el mayor número de estructuras negativas son los valores de logro y de capacidad. En este punto, sí creemos que se está configurando una nueva construcción gramatical especializada en la expresión de valores gramaticales vinculados a la frustratividad.

\begin{tabular}{|l|l|l|l|l|l|l|}
\hline Siglo & Polaridad & $\begin{array}{l}\text { Valor } \\
\text { conclusivo }\end{array}$ & Capacidad & Focalizador & Logro & $\begin{array}{l}\text { Posibili- } \\
\text { dad }\end{array}$ \\
\hline \multirow{2}{*}{ XIII } & afirmativa & $100 \%(2 / 2)$ & $100 \%(2 / 2)$ & ---- & $\begin{array}{l}100 \% \\
(2 / 2)\end{array}$ & ---- \\
\cline { 2 - 8 } & negativa & ---- & ---- & ---- & ---- & ---- \\
\hline \multirow{2}{*}{ XIV } & afirmativa & $100 \%(1 / 1)$ & $100 \%(3 / 3)$ & ---- & ---- & ---- \\
\hline \multirow{2}{*}{ XV } & afirmativa & $100 \%(2 / 2)$ & ---- & ---- & ---- & ---- \\
\cline { 2 - 7 } & negativa & ---- & $100 \%(1 / 1)$ & ---- & ---- & ---- \\
\hline
\end{tabular}




\begin{tabular}{|c|c|c|c|c|c|c|}
\hline \multirow[t]{2}{*}{ XVI } & afirmativa & $\begin{array}{l}95,5 \% \\
(21 / 22)\end{array}$ & $\begin{array}{l}80 \% \\
(16 / 20)\end{array}$ & $\begin{array}{l}95,4 \% \\
(42 / 44)\end{array}$ & $\begin{array}{l}97,5 \% \\
(39 / 40)\end{array}$ & ---- \\
\hline & negativa & $4,5 \%(1 / 22)$ & $20 \%(4 / 20)$ & $\begin{array}{l}4,5 \% \\
(2 / 44)\end{array}$ & $\begin{array}{l}2,5 \% \\
(1 / 40)\end{array}$ & ---- \\
\hline \multirow[t]{2}{*}{ XVII } & afirmativa & $\begin{array}{l}95,2 \% \\
(20 / 21)\end{array}$ & $\begin{array}{l}83,7 \% \\
(36 / 43)\end{array}$ & $\begin{array}{l}88,6 \% \\
(39 / 44)\end{array}$ & $\begin{array}{l}98 \% \\
(51 / 52)\end{array}$ & $\begin{array}{l}50 \% \\
(1 / 1)\end{array}$ \\
\hline & negativa & $4,8 \%(1 / 21)$ & $\begin{array}{l}16,27 \% \\
(7 / 43)\end{array}$ & $\begin{array}{l}11,36 \% \\
(5 / 44)\end{array}$ & $2 \%(1 / 52)$ & $\begin{array}{l}50 \% \\
(1 / 1)\end{array}$ \\
\hline \multirow[t]{2}{*}{ XVIII } & afirmativa & $\begin{array}{l}76,9 \% \\
(20 / 26)\end{array}$ & $75 \%(9 / 12)$ & $\begin{array}{l}95,8 \% \\
(23 / 24)\end{array}$ & $\begin{array}{l}92,85 \% \\
(13 / 14)\end{array}$ & $\begin{array}{l}100 \% \\
(2 / 2)\end{array}$ \\
\hline & negativa & $23 \%(6 / 26)$ & $25 \%(3 / 12)$ & $\begin{array}{l}4,1 \% \\
(1 / 24)\end{array}$ & $\begin{array}{l}7,14 \% \\
(1 / 14)\end{array}$ & ---- \\
\hline \multirow[t]{4}{*}{ XIX } & afirmativa & $\begin{array}{l}82,2 \% \\
(116 / 141)\end{array}$ & $\begin{array}{l}79,2 \% \\
(61 / 77)\end{array}$ & $\begin{array}{l}93,8 \% \\
(183 / 195)\end{array}$ & $\begin{array}{l}78,5 \% \\
(73 / 93)\end{array}$ & $\begin{array}{l}61,1 \% \\
(11 / 18)\end{array}$ \\
\hline & $\begin{array}{l}\text { afirmativa } \\
\text { neg.ante inf }\end{array}$ & ---- & ---- & $\begin{array}{l}0,51 \% \\
(1 / 195)\end{array}$ & ---- & ---- \\
\hline & $\begin{array}{l}\text { negación } \\
\text { ante inf }\end{array}$ & ---- & ---- & $\begin{array}{l}0,51 \% \\
(1 / 195)\end{array}$ & ---- & ---- \\
\hline & negativa & $\begin{array}{l}17,7 \% \\
(25 / 141) \\
\end{array}$ & $\begin{array}{l}16,88 \% \\
(13 / 77) \\
\end{array}$ & $\begin{array}{l}5,1 \% \\
(10 / 195)\end{array}$ & $\begin{array}{l}21,5 \% \\
(20 / 93) \\
\end{array}$ & $\begin{array}{l}33,3 \% \\
(6 / 18)\end{array}$ \\
\hline \multirow[t]{2}{*}{$\mathrm{xx}$} & afirmativa & $\begin{array}{l}74,6 \% \\
(94 / 126)\end{array}$ & $\begin{array}{l}65 \% \\
(52 / 80)\end{array}$ & $\begin{array}{l}74 \% \\
(148 / 200)\end{array}$ & $\begin{array}{l}64,2 \% \\
(63 / 98)\end{array}$ & $\begin{array}{l}83,3 \% \\
(5 / 6)\end{array}$ \\
\hline & negativa & $\begin{array}{l}22,2 \% \\
(28 / 126)\end{array}$ & $\begin{array}{l}35 \% \\
(28 / 80)\end{array}$ & $\mid \begin{array}{l}22 \% \\
(44 / 200)\end{array}$ & $\begin{array}{l}34,69 \% \\
(34 / 98)\end{array}$ & $\begin{array}{l}16,6 \% \\
(1 / 6)\end{array}$ \\
\hline
\end{tabular}

Tabla 19. Polaridad y empleo de la perífrasis llegar $a+$ INF

\subsection{LOS ENCADENAMIENTOS PERIFRÁSTICOS Y LOS SENTIDOS CONTRAFÁCTICOS}

El desarrollo de los valores focalizadores, ya sean en su versión más fuerte, como sinónimos de incluso, ya sea en su versión más atenuada, pudo ser el detonante para la introducción de la perífrasis en un entorno de encadenamiento perifrástico y en contextos contrafácticos (para el concepto y las repercusiones lingüísticas del concepto de encadenamiento perífrástico, vid. Bravo, García Fernández y Krivochen 2015). La pregunta que cabe responder aquí es si estamos ante la creación de nuevos patrones que emparejan forma y significado. Esto es, ¿podemos plantear la hipótesis de que poder + llegar a + INF constituye una construcción gramatical con 
entidad propia? O, por el contrario, ¿esta estructura encadenada es uno de los ámbitos de empleo de llegar a + INF? Y de la misma manera cabe formularse la pregunta de si se ha constituido una construcción contrafáctica que añada un nuevo contexto de empleo para llegar $a+\mathrm{INF}$.

La productividad tanto del esquema de encadenamiento perifrástico como de la condicional contrafáctica aumenta en nuestro corpus con el transcurso de los siglos. Así, en lo referente a los encadenamientos, se pasa de un empleo apenas destacado en la Edad Media a las 24 ocurrencias por millón de palabras en la lengua contemporánea (vid. Tabla 20). Esta cifra debe ser puesta en comparación con el empleo total de la perífrasis, puesto que de este modo se constata que de las 200 ocurrencias de la perífrasis por millón de palabras más de un $10 \%$ corresponden a encadenamientos.

\begin{tabular}{|c|c|c|c|}
\hline Siglo & Frecuencia absoluta & $\mathrm{N}^{\circ}$ palabras & $\begin{array}{l}\text { Frecuencia por } \\
\text { millón de palabras }\end{array}$ \\
\hline XVI & 6 & 3603987 & 1,66 \\
\hline XVII & 11 & 2108281 & 5,21 \\
\hline XVIII & 3 & 1309491 & 2,29 \\
\hline XIX & 12 & 1916754 & 6,26 \\
\hline $\mathrm{xx}$ & 61 & 2542573 & 23,99 \\
\hline
\end{tabular}

Tabla 20. Encadenamientos perifrásticos con llegar a + INF

En lo relativo a las construcciones contrafácticas, aun resultando menos habituales, los datos nos permiten constatar que, mientras que hasta el siglo XIX la presencia de esta construcción es inexistente o prácticamente inexistente, a partir del ochocientos casi representa 10 ocurrencias por millón de palabras del total de empleos de la perífrasis ( $c f$. Tabla 21).

\begin{tabular}{|l|l|l|l|}
\hline Siglo & Frecuencia absoluta & $\mathrm{N}^{\mathrm{o}}$ palabras & $\begin{array}{l}\text { Frecuencia por } \\
\text { millón de palabras }\end{array}$ \\
\hline XVII & 2 & 2108281 & 0,94 \\
\hline XVIII & 1 & 1309491 & 0,76 \\
\hline XIX & 18 & 1916754 & 9,39 \\
\hline XX & 18 & 2542573 & 7,07 \\
\hline
\end{tabular}

Tabla 21. Llegar $a+\mathrm{INF}$ en condicionales contrafácticas 
Sin embargo, no creemos que este aumento de frecuencia sea indicativo de la emergencia de nuevas construcciones gramaticales. El valor de llegar a + INF en todas ellas es el focalizador atenuado que hemos reseñado en el apartado 5.2.1. Así pues, más parece que el despegue de contextos de empleo de llegar $a+$ INF pueda tener que ver con el asentamiento de su valor focalizador.

\subsubsection{Los encadenamientos poder/deber + llegar $a+$ inf}

Los encadenamientos perifrásticos de llegar $a+$ INF suponen su aparición en la segunda posición de un encadenamiento perifrástico encabezado por poder $\mathrm{y}$ en menor medida por deber. Esto es, se trata de secuencias como las de (25) y (26) que, como hemos señalado, alcanzan un porcentaje progresivamente relevante en nuestro corpus.

25. \& enbargados con el estudio del aprender . desanparan alos que deujan defender . \&' asy piensa platon que estos non deurian llegar a admjnjstrar la Republjca saluo apremjados. (Alonso de Cartagena, De los oficios, siglo xv, Gradia)

26. Y le dijo el doctor que, en realidad, toda anestesia... por la mejor que sea, siempre tienen un riesgo... Mínimo o mayor... este... que puede... llegar a afectar la columna, ya que tiene tantas ramificaciones, y médulas y... tiene que ser tan exacta, que podría llegar a afectarla. (Juan M. Lope Blanch, El habla popular de la ciudad de México. Materiales para su estudio, siglo xx, GRADIA)

Como se ve en (25) y (26), la diferencia entre la forma verbal simple y la forma con encadenamiento como es lógico depende de la presencia de llegar $a+$ INF, que añade el significado de que el evento expresado por el infinitivo tiene lugar tras un recorrido previo. Esto es, llegar $a+$ INF funcionaría como un pressupositional trigger que permitiría interpretar que el evento expresado por el infinitivo no se produce de manera inmediata, sino tras una secuencia de tiempo previa más o menos larga. Además, entre no deberían llegar a administrar la República y no deberían administrar la República, por un lado, y puede llegar a afectar la columna y puede afectar la columna, por el otro, hay una diferencia relativa al menor compromiso del hablante sobre la veracidad o la probabilidad de cumplimiento del evento expresado por administrar en (25) y afectar en (26). Así, llegar a afectar crea un efecto atenuador, respecto del carácter más categórico de una afirmación como puede afectar. Otro tanto sucede con no deberían llegar a administrar, que resulta menos tajante que no deberían administrar. 


\subsection{LOS CONTEXTOS CONTRAFÁCTICOS Y LA PERÍFRASIS LLEGAR A + INF}

Tradicionalmente, se ha atribuido un valor contrafáctico a la perífrasis llegar a + INF cuando aparece en la prótasis de oraciones condicionales. Esto supondría la existencia de una nueva construcción gramatical articulada en torno a llegar a + INF. Sin embargo, como se ha señalado, el análisis de los ejemplos parece indicar que el sentido contrafáctico es característico de las oraciones condicionales en las que aparece la perífrasis (para un análisis de las condicionales contrafácticas, vid. Montolío Duran 1999). Si comparamos la construcción con llegar $a+\operatorname{INF}$ (27a) con la correspondiente estructura contrafáctica sin esta perífrasis (27b), se observa que la diferencia no tiene que ver con la factualidad de la acción expresada por la prótasis condicional. Tan contrafáctica resulta, ;Anda que si lo sé/hubiese sabido...! como ;Anda que si lo llego a saber...!

26. a. ¿Y tú, cómo no me has dicho antes que eras el sobrino pequeño de Andrés? ¡Anda que, si lo llego a saber...! (Almudena Grandes, Inés y la alegría, siglo XXI, GRADIA)

b. ¡Anda que si lo sé...!

La diferencia entre (27a) y (27b) radica en el matiz focalizador del evento expresado por el infinitivo, que tiene que ver con la persistencia de un valor de recorrido ligado al empleo del verbo llegar. Llego a saber introduce un sentido de dificultad para que el hablante pudiese haber sabido que su interlocutor es el sobrino de Andrés. Este sentido de dificultad, que a menudo se percibe en el empleo de esta perífrasis, se aviene bien con el valor contrafáctico de este tipo de oraciones condicionales que expresan valores no reales con el verbo en presente de indicativo. Así pues, lo que si acaso cabe explicar es la especial afinidad de llegar a + INF por este tipo de construcciones. La explicación la tenemos en los sentidos pragmáticos de énfasis que rodean a esta construcción habilitándola de este modo para que se emplee en contextos en los que se quiere enfatizar lo irreal de un supuesto.

\section{CONCLUSIÓN Y DISCUSIÓN DE LOS RESULTADOS}

En este artículo hemos trabajado con la hipótesis de que llegar a + INF no es una perífrasis aspectual. Hemos constatado, además, que la perífrasis existía ya en período medieval, cuando, aun con baja frecuencia de uso, 
se documenta ya con valores conclusivos, de logro y capacidad. Cada uno de estos significados se combina con una estructura lo suficientemente individualizada como para poder defender que estamos ante construcciones gramaticales diferentes. El siglo XVI marca la emergencia de los significados focalizadores. En el siglo XVII surge una nueva construcción gramatical, ligada a la expresión de la posibilidad. De este modo, llegar a + INF conforma una categoría radial que puede representarse como sigue:

\begin{tabular}{|c|c|c|c|c|}
\hline FORMA & & FORMA & & FORMA \\
\hline $\begin{array}{l}\text { [llegar a INF] } \\
\text { Suj [ } \pm \text { animado, } \\
\quad \text { - volitivo] } \\
\text { Aux, }[ \pm \text { perfectivo }] \\
\text { Auxiliado } \\
\text { (principalmente) } \\
\text { [estados, logros] }\end{array}$ & $\leftrightarrow$ & \begin{tabular}{|l|} 
[llegar a INF] $]$ \\
Suj [+animado, \\
$\quad$ +volitivo] \\
Aux, [+ perfectivo] \\
Auxiliado \\
(principalmente) \\
[estados, logros]
\end{tabular} & $\leftrightarrow$ & \begin{tabular}{|l} 
[llegar a INF]] \\
Suj [+animado, \\
$\quad \pm$ volitivo] \\
Aux, [- perfectivo] \\
Auxiliado \\
(principalmente) \\
[estados, logros]
\end{tabular} \\
\hline SIGNIFICADO & & SIGNIFICADO & & SIGNIFICADO \\
\hline $\begin{array}{l}\text { Final de una serie de } \\
\text { acciones previas }\end{array}$ & & Logro & & Capacidad \\
\hline$\downarrow$ & & & & $\downarrow$ \\
\hline FORMA & & & & FORMA \\
\hline \begin{tabular}{|l} 
[llegar a INF] $]$ \\
Suj [ \pm animado, \\
$\quad$ volitivo] \\
Aux, $[ \pm$ perfectivo] \\
Auxiliado \\
(principalmente) \\
[estados, \\
logros], también \\
realizaciones \\
\end{tabular} & & & & \begin{tabular}{|l} 
[llegar a INF]] \\
Suj [- animado] \\
Aux, [- perfectivo] \\
Auxiliado \\
(principalmente) \\
[estados, logros]
\end{tabular} \\
\hline SIGNIFICADO & & & & SIGNIFICADO \\
\hline Focalización & & & & Posibilidad \\
\hline
\end{tabular}


Los sentidos focalizadores fueron, a su vez, el detonante de un empleo remarcable de la perífrasis en la prótasis de oraciones condicionales contrafácticas y como segundo elemento de cadenas de perífrasis encabezadas por el verbo poder y, en menor medida, por deber. Además, una nueva construcción gramatical especializada en la expresión de la frustratividad parece haberse desarrollado en la combinación de llegar a + INF con la negación. Por último, el complejo desarrollo de llegar a + INF parece haber consolidado también una construccionalización léxica: llegar a ser parece haberse constituido en el correlato español de los verbos léxicos del francés y del inglés devenir y become ${ }^{11}$.

Si ampliamos la mirada y situamos llegar a + INF en el paradigma de las perífrasis verbales del español, se puede constatar que su evolución presenta una línea de cambio que se ve afectada por la existencia de otras perífrasis cuasisinónimas, a saber, lograr + INF y conseguir + INF. La evolución de estas perífrasis se suma a la de alcanzar + INF y uviar + INF, de manera que a partir del siglo XviII podemos sostener que se ha creado un esquema gramatical que podríamos formalizar como [X alcanzar $\mathrm{Y}]$. Este, a su vez, se concretaría en varios subesquemas correspondientes a las perífrasis verbales mencionadas: lograr + INF, conseguir + INF, alcanzar + INF, uviar + INF y llegar a + INF. Esto significa que la evolución de estas perífrasis, en un principio reducidas a alcanzar + INF, uviar + INF y llegar a + INF, llevó a abstraer un patrón de construcción más general que, incluso permitió interferencias en la evolución de todas ellas. La arcaizante y dialectal, además de formalmente extraña, $u v i a r+\mathrm{INF}$ fue arrinconada por alcanzar a + INF y llegar $a+\mathrm{INF}$ (Garachana Camarero 2016). A su vez, estas perdieron terreno bajo la presión de lograr + INF y conseguir + INF. Se observa así un entramado de relaciones que, siguiendo con la idea de Saussure de que la lengua es un sistema donde todo está relacionado ('La langue est un système où tout se tient', Saussure 1916), propician desarrollos puntuales de determinadas perífrasis verbales. En futuros trabajos, vamos a desarrollar esta línea de investigación.

11 Como señala uno de los revisores anónimos, no es fácil sostener que llegar a ser es el resultado de una lexicalización, habida cuenta de que su funcionamiento (como el de become y devenir) es el de una semicópula. Una vez más, como se sostiene desde la gramática de construcciones, los límites entre el léxico y la gramática resultan poco nítidos. 


\section{REFERENCIAS BIBLIOGRÁFICAS}

\section{BASES DE DATOS}

GRADIA $=$ Corpus del grupo de investigación Gradia, $<$ http://Gradiadiacronia.wix.com/Gradia $>$.

\section{BiBLIOGRAFÍA}

Bouzouita, Miriam. 2012. Los futuros analíticos y sintéticos en la 'Fazienda de Ultra Mar. En Emilio Montero y Carmen Manzano (eds.). Actas del VIII congreso internacional de historia de la lengua española, 695-706. España: Meubook.

Boye, Kasper y Peter Harder. 2012. A usage-based theory of grammatical status and grammaticalization. Language 88 (1): 1-44.

Bravo, Ana, Luis García Fernández y Diego Gabriel Krivochen. 2015. On auxiliary chains: Auxiliaries at the syntax-semantics interface. Borealis 4 (2): 71-101.

Bravo Martín, Ana. 2014. "The Spanish auxiliary ir 'to go': from resultative motion verb to focus marker". En Maud Devos y Jenneke van der Wal (eds.). COME and GO'off the Beaten Grammaticalization Path", pp. 305-51. Berlin-Boston: Mouton de Gruyer.

Carrasco Gutiérrez, Ángeles. 2006. Llegar a + infinitivo. En Luis García Fernández (dir.). Diccionario de perifrasis verbales, pp. 186-92. Madrid: Gredos.

2008. <Llegar a + infinitivo> como conector aditivo en español. Revista española de lingüística 38 (1): 67-94.

Camus Bergareche, Mario. 2006. Dejar de + infinitivo. En Luis García Fernández (dir.), Diccionario de perifrasis verbales, pp. 117-20. Madrid: Gredos.

Dietrich, Wolf. 1983. El aspecto verbal perifrástico en las lenguas románicas: estudios sobre el actual sistema verbal de las lenguas románicas. Madrid: Gredos.

Fente Gómez, Rafael, Jesús Fernández Álvarez y Lope G. Feijóo. 1979. Perífrasis verbales. Madrid: Sociedad General Española de Librería.

FernáNDEZ De CASTRO, Félix. 1999. Las perifrasis verbales en el español actual. Madrid: Gredos.

Fillmore, Charles J. 1988. The mechanisms of 'Construction Grammar'. En Berkeley Linguistics Society 14: General Session and Parasession on Grammaticalization, pp. 35-55. Berkeley, CA: Berkeley Linguistics Society.

Fillmore, Charles J. y Paul Kay. 1997. Berkeley Construction Grammar. http://www1.icsi. berkeley.edu/ kay/bcg/ConGram.html.

Fillmore, Charles J., Paul Kay y Mary Catherine O'Connor. 1988. Regularity and idiomaticity in grammatical constructions. Language 64: 501-38.

FogsgaArd, Lene. 2002. Algunas perifrasis aspectuales del español. Alicante: Universidad de Alicante.

Garachana Camarero, Mar. 2008. Cuestiones pragmáticas sobre la negación. RedEle 12.

2016. Verbos de movimiento y perífrasis verbales en español medieval : "uviar" (a) + infinitivo. Revista de Historia de la Lengua Española 11: 59-87.

2017a. Las perífrasis verbales en una perspectiva histórica. En Mar Garachana (ed.). La gramática en la diacronía. La evolución de las perifrasis verbales modales en español, 9-33. Madrid - Frankfurt: Iberoamericana-Vervuert.

2017b. Los límites de una categoría híbrida. Las perífrasis verbales. En Mar Garachana (ed.). La gramática en la diacronía. La evolución de las perifrasis verbales modales en español, pp. 35-80. Madrid-Frankfurt: Iberoamericana-Vervuert. 
2019. De cuando "ir a + InfInITIvo" no se dirige al futuro. Construcciones gramaticales de pasado, aspecto culminativo y sentido focalizador, una aproximación desde la gramática de construcciones. Revista Española de Lingüistica 49.

García Fernández, Luis (dir.), Ángeles Carrasco Gutiérrez, Bruno Camus Bergareche, María Martínez Atienza y Mª́ngeles García García-Serrano. 2006. Diccionario de perifrasis verbales. Madrid: Gredos.

García Fernández, Luis y Ángeles Carrasco Gutiérrez. 2008. Perífrasis verbales con función de marcador del discurso. Contrarréplica a Olbertz (2007). Verba 35: 439-47.

García GonzÁlez, Javier. 1992. Perifrasis verbales. Madrid: Sociedad General Española de Librería (1998 segunda edición).

Gili y Gaya, Samuel. 1961. Curso superior de sintaxis española. Barcelona: Biblograf.

Goldberg, Adele E. 1995. Constructions: A Construction Grammar Approach to Argument Structure. Chicago: Chicago University Press.

2006. Constructions at Work: The Nature of Generalization in Language. Oxford: Oxford University Press.

Gómez Manzano, Pilar. 1992. Perífrasis verbales con infinitivo: (valores y usos en la lengua hablada). Madrid: UNED.

Gómez Torrego, Leonardo. 1988. Perífrasis verbales. Sintaxis, semántica y estilística. Madrid: Arco Libros.

1999. Los verbos auxiliares. Las perífrasis verbales de infinitivo. En Ignacio Bosque y Violeta Demonte (eds.). Gramática Descriptiva de la Lengua Española, pp. 3323-89. Madrid: Espasa-Calpe.

Hilferty, Joseph, Javier Valenzuela y Mar Garachana. 2005. On the reality of constructions: The Spanish reduplicative-topic construction. Annual Review of Cognitive Linguistics 3: 201-215.

HiLPERT, MARTIN. 2013. Constructional change in English: Developments in allomorphy, word formation and syntax. Cambridge: Cambridge University Press.

2018. Three open questions in Diachronic Construction Grammar. En Evie Coussé, Peter Andersson y Joel Olofsson (eds.). Grammaticalization meets Construction Grammar, pp. 21-39. Amsterdam /Philadelphia: John Benjamins.

HopPer, PAul J. 1991. On some Principles of Grammaticalization. En Elizabeth Closs Traugott y Bernd Heine (eds.). Approaches to grammaticalization, Vol. 1., pp. 17-35. Amsterdam /Philadelphia: John Benjamins.

Kay, Paul y Charles J. Fillmore. 1999. Grammatical constructions and linguistic generalizations: The What's X doing Y? construction. Language 75: 1-34.

Lakoff, George. 1987. Women, Fire, and Dangerous Things: What Categories Reveal about the Mind. Chicago: University of Chicago Press.

Medina Urrea, Alfonso y Concepción Company Company. 1999. Sintaxis motivada pragmáticamente: futuros analíticos y futuros sintéticos en el español medieval. Revista de filología española 79 (1-2): 65-100.

Montolío Duran, Estrella. 1999. Las construcciones condicionales. En Ignacio Bosque y Violeta Demonte (eds.). Gramática Descriptiva de la Lengua Española, pp. 3643-3738. Madrid: Espasa Calpe.

Morera Pérez, Marcial. 1991. Diccionario crítico de las perífrasis verbales del español. Puerto del Rosario: Servicio de Publicaciones del Cabildo Insular de Fuerteventura.

Olbertz, Hella. 1998. Verbal periphrases in a functional grammar of Spanish. Berlin/ New York: Walter de Gruyter.

Pountain, Christopher J. 1984. How "become" became in Castilian. En Richard A. Cardwell (ed.). Essays in honour of Robert Brian Tate from his colleagues and pupils, pp. 101-11. Nottingham: University of Nottingham Monographs in the Humanities. 
RAE y ASALE. 2009. Nueva Gramática de la Lengua Española. Madrid: Espasa.

Rosemeyer, Malte y Mar Garachana. 2019. De la consecución a la contraexpectación: la construccionalización de lograr/conseguir + infinitivo. Studies in Hispanic and Lusophone Linguistics.

Saussure, Ferdinand 1916. Cours de Linguistique Générale. Paris: Grande Bibliothèque Payot.

Smirnova, Elena. 2015. Constructionalization and constructional change: The role of context in the development of constructions. En Joana Barðdal, Elena Smirnova, Lotte Sommerer y Spike Gildea (eds.). Diachronic Construction Grammar, pp. 81-106. Amsterdam / Philadelphia: John Benjamins.

Sweetser, Eve. 1991. From Etymology to Pragmatics. Metaphorical and Cultural Aspects of Semantic Structure. Cambridge: Cambrigde University Press.

Traugott, Elizabeth Closs y Graeme Trousdale. 2013. Constructionalization and Constructional Changes. Oxford: Oxford University Press.

Yllera, Alicia. 1980. Sintaxis histórica del verbo español: las perífrasis medievales. Zaragoza: Departamento de Filología Francesa. Universidad de Zaragoza. 